\title{
WestVirginiaUniversity
}

THE RESEARCH REPOSITORY @ WVU

Graduate Theses, Dissertations, and Problem Reports

2010

\section{Equine Assisted Activities and Therapies}

\author{
Carol C. Petitto \\ West Virginia University
}

Follow this and additional works at: https://researchrepository.wvu.edu/etd

\section{Recommended Citation}

Petitto, Carol C., "Equine Assisted Activities and Therapies" (2010). Graduate Theses, Dissertations, and Problem Reports. 3203.

https://researchrepository.wvu.edu/etd/3203

This Dissertation is protected by copyright and/or related rights. It has been brought to you by the The Research Repository @ WVU with permission from the rights-holder(s). You are free to use this Dissertation in any way that is permitted by the copyright and related rights legislation that applies to your use. For other uses you must obtain permission from the rights-holder(s) directly, unless additional rights are indicated by a Creative Commons license in the record and/ or on the work itself. This Dissertation has been accepted for inclusion in WVU Graduate Theses, Dissertations, and Problem Reports collection by an authorized administrator of The Research Repository @ WVU.

For more information, please contact researchrepository@mail.wvu.edu. 


\title{
Equine Assisted Activities and Therapies
}

\author{
Carol C. Petitto \\ Dissertation submitted to the Davis College of Agriculture, Natural \\ Resources and Design at West Virginia University in partial fulfillment of \\ the requirements for the degree of \\ Doctor of Philosophy \\ In \\ Human and Community Development \\ Dr. Dennis K. Smith, Ph.D., Chair \\ Dr. MaryBeth Mandich, P.T., Ph.D. \\ Dr. Tim T. Phipps, Ph.D. \\ Lesley Shear \\ Dr. Mary Ellen Zeppuhar, Ph.D. \\ Division of Resource Management
}

Morgantown, West Virginia

2010

Keywords: Equine assisted activities and therapies, EAAT, autism, measurement outcomes, college curricula, therapeutic riding Copyright 2010 Carol C. Petitto 


\section{ABSTRACT \\ Equine Assisted Activities and Therapies}

\section{Carol C. Petitto}

This dissertation is composed of three essays in which each carefully examines an important aspect of the field of equine assisted activities and therapies (EAAT). In the first essay, I review how equine assisted activities and therapies should be considered as an early intervention to help facilitate communication skills in children with autism. The majority of participants in NARHA programs have autism, and therefore it is critical to appraise the validity of EAAT as a positive intervention. Respondents of NARHA centers to a survey on their use of assessments in tracking the progress of their participants indicated that only $7 \%$ of centers utilized assessment forms specifically for autism. Research in the effects of EAAT on children with autism is extremely limited. NARHA centers that are seeing success with EAAT as an intervention for communication disorders should be more vigilant in documenting their results in a meaningful way.

The second essay explores the educational aspects of the field of equine assisted activities and therapies. College and universities are trying to meet the demand of students to provide curricula for training and instructor certification. This demand cannot be met unless the curricula are carefully designed and partnerships are in place with NARHA member centers. Of the NARHA centers responding to a survey, $41 \%$ currently had a partnership or affiliation with a college or university. $11 \%$ had direct involvement with a college or university EAAT curriculum. The relationships between NARHA centers and colleges and universities should be developed in order to offer quality services by the professionals involved in the EAAT field, and appropriate curricula by the colleges and universities.

The final essay examines developing procedures for therapeutic riding instructors and centers to measure participant progress and outcomes. This is important in terms of proving the success of their programming. The validity of their efforts needs to be shown to medical professionals, families and insurance companies for referral and reimbursement purposes. A survey conducted in 2009 of NARHA Premier Accredited Centers showed a diversity of record keeping and types of assessments. Written assessments were used by $46 \%$ of the centers, $35 \%$ of the respondents used checklists, and $17.6 \%$ used scoring methods. The range of sizes and programming for NARHA centers may inhibit the possibilities for producing an assessment form that is universally useful for therapeutic riding instructors and centers. However, an attempt should be made to develop a format that all centers can use simply and efficiently to allow improvement and efficiency of rider assessments. 


\section{Acknowledgements}

My sincere appreciation goes out to Dr. Dennis Smith, chairman of my committee, whose vision, enthusiasm, and support for this project cannot be conveyed in mere words. His ability to see diamonds when others see rust has been a rare and valuable inspiration to me. He has brought about a fundamental change in my life that hopefully, in turn, will help many others with the quality of their lives. My other committee members, Dr. MaryBeth Mandich, Dr. Tim T. Phipps, Lesley Shear, and Dr. Mary Ellen Zeppuhar also played an integral part in the success of my course of study. I want to especially thank my husband Jim, and sons Michael and Brian Petitto, for their extraordinary patience, support and understanding throughout the undertaking of this project. I also want to extend my profound appreciation to the participants, friends, volunteers and special horses that have been such an important part of this educational trail.

I would like to dedicate this body of work to my parents, John and Leona Cordyack. Although they did not live to see the fulfillment of this dream, they instilled in me the belief that I was capable of good things, as in my father's favorite quote - "I expect to pass through this world but once: if therefore, there be any kindness I can show, or any good thing I can do, let me do it now; let me not defer or neglect it, for I shall not pass this way again." The completion of this course of study and the development of On Eagles' Wings Therapeutic Riding Center is a testimony to their unwavering faith in me and what I was capable of accomplishing in my life. 


\section{Table of Contents}

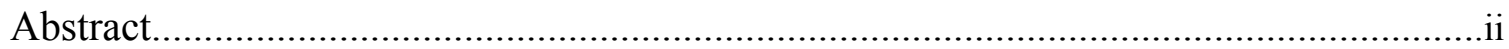

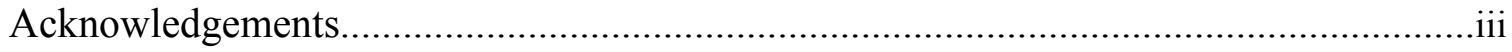

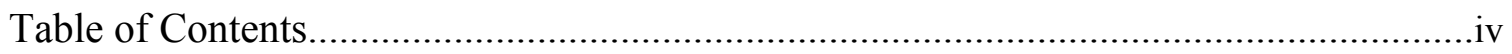

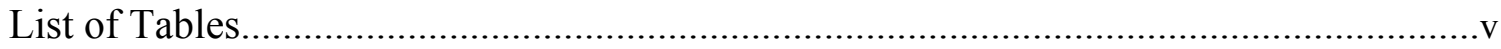

Chapter 1: The Use of Equine Assisted Activities and Therapies (EAAT) As Early/Treatment Interventions for Communication Disorders for Children With Autism...... 1

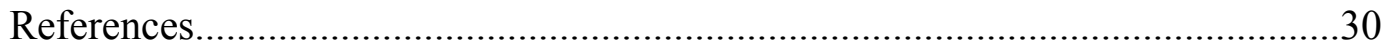

Chapter 2: College Curricula for Equine Assisted Activities and Therapies....................38

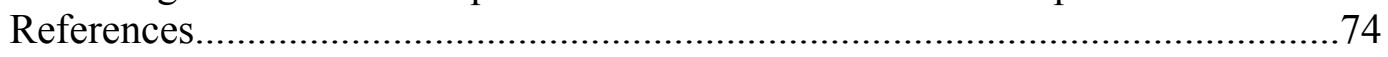

Chapter 3: Measurement of Outcomes For Therapeutic Riding Instructors

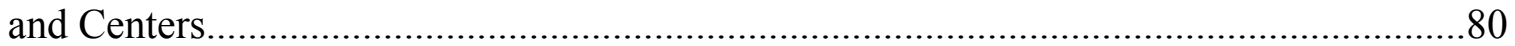

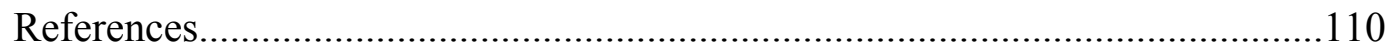

Appendices

APPENDIX A Measurement Outcome Form for Autism Disorder....................115

APPENDIX B Course and Department Suggestions for EAAT Curricula.........119

APPENDIX C Measurement Outcome Form for NARHA center use.................121 


\section{List of Tables}

\section{Essay 1}

Table 1: Types of communication assessments based on survey of NARHA centers.

Table 2: Premier Accredited NARHA Center survey. .29

\section{Essay 2}

Table 1: Universities and Colleges in the United States that Offer Equine Assisted

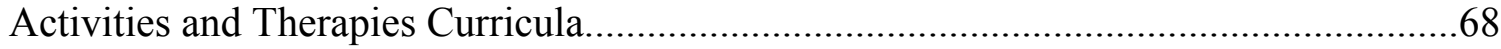

Table 2: Premier Accredited NARHA Center survey................................................... 72

Table 3: University or college and NARHA relationships based on survey results.....73

\section{Essay 3}

Table 1: NARHA Mandatory Standards. 106

Table 2: Premier Accredited NARHA Center survey. 107

Table 3: Measurement of Outcomes and/or Rider Progress for NARHA centers. .108 


\title{
CHAPTER 1: ESSAY 1
}

\section{The Use of Equine Assisted Activities and Therapies (EAAT) As Early/Treatment Interventions for Communication Disorders in Children with Autism Disorders}

\author{
Carol C. Petitto \\ West Virginia University \\ Davis College of Agriculture, Natural Resources and Design
}




\section{The Use of Equine Assisted Activities and Therapies (EAAT) As Early/Treatment Interventions for Communication Disorders in Children with Autism Disorder}

Professionals actively involved in the field of equine assisted activities and therapies are aware of the positive effects that horses have on children with autism. Specific studies on equine assisted activities and therapies and their effects on children with autism are scarce and the need for research is important because of the rapid rise in the numbers of children diagnosed with autism. There is also a growing acknowledgment from those involved in diagnosing, treating and researching children with autism that early intervention therapies are critical for their development of communication skills.

NARHA, the North American Riding for the Handicapped Association, is the primary international organization that oversees the fast-growing field of equine assisted activities and therapies. Autism disorder is currently the most served disability at NARHA centers nationwide (NARHA, 2009). According to the NARHA 2009 fact sheet, participants in NARHA programs with autism have increased by 6\% in four years. NARHA conducts certifications for therapeutic riding instructors, maintains standards and guidelines for participating member equine assisted activity centers, and provides educational support for parents, participants and instructors. They also partner with several other associations that are involved with equine assisted activities and therapies, including the American Hippotherapy Association (AHA) and the Equine Facilitated Mental Health Association (EFMHA). There are several different specialties within the field of equine assisted activities and therapies that currently serve autism spectrum disorders, including hippotherapy, therapeutic riding, equine facilitated learning and equine facilitated 
psychotherapy. Hippotherapy professionals use the movement of the horse to provide physical therapy, occupational therapy and speech-language therapy. (McGibbon, Benda, Duncan \& Silkwood-Sherer, 2009). Therapeutic riding instructors certified by NARHA are trained to use the horse to give riding lessons. Driving and vaulting are other specialties that require certification (NARHA, 2009). Equine facilitated learning (EFL) and equine facilitated psychotherapy (EFP) specialists use horses to interact with their clients to improve mental and emotional disabilities (EFMHA, 2009). NARHA member centers employ therapeutic riding instructors as well as specialists that practice hippotherapy, EFL and EFP.

Much of the past research involving equine assisted activities and therapies has focused on cerebral palsy and other physical disabilities (Hubbard, 2007). The continual rise in numbers of children diagnosed with autism (CDC, 2009) has created an almost epidemic need to do research on autism and help find suitable treatments and possible cures. The validity of equine assisted activities and therapies as an intervention tool for autism needs to be researched as well, but producing reliable assessments given the multifaceted characteristics of autism is a difficult hurdle.

\section{What is Autism Disorder?}

The official diagnostic manual for mental disorders for health professionals, the Diagnostic and Statistical Manual of Mental Disorders, Fourth Edition, (DSM-IV; American Psychiatric Association, 2000), defines autism disorder under a group of disorders called Pervasive Developmental Disorders (PDD). Autism disorder is characterized by communication and social impairments, as well as severe 
restrictions on interests and activity involvement. Children with autism may have impairment with eye-to-eye gaze and ability to read facial expressions, and usually lack social reciprocity. They often have repetitive and ritualized patterns of behavior, including strict adherence to routines. Preoccupation with objects or parts of objects is common, as well as repetitive motor mannerisms, including hand flapping and other forms of self-stimulation. Sensory issues may be present, including sensitivity to noise, certain types of lighting and tactile problems. Both the social and communication impairments can be severe, and in particular, the communication problems will be with both verbal and nonverbal skills. The DSM-IV also specifies there must be a total of six impairments in three criterion areas, including social interaction deficits (Criterion A), dysfunction or delays in social communication that begin before age 3 (Criterion B), and the exclusion of more appropriate diagnoses (Criterion C). Criterion A2 focuses on the verbal and nonverbal communication deficits. These deficits can range from fluent speech with problems with semantics or appropriate use of language, to the lack of spoken language with no other attempts to communicate, such as with gestures.

Although there are few studies based on the parents' perceptions about their children's social and communicative skills, it certainly can be surmised that lack of speech and language is the major concern. Hoppe (2005) examined parent perceptions on communication problems with their children with autism. Parents involved in the interview-based study indicated that communication problems contributed to challenging behaviors and "inhibited everything their child tried to accomplish". A recent study in Great Britain examined parents' priorities regarding 
their concerns for their children with autism. Parents indicated their top worry about their children was "the young person's progress in terms of social skills" (Whitaker, 2007). The exact numbers of children with autism and severe communication disorders varies from study to study, but estimates range from onequarter to one-half of the population (Luyster, Kadlec, Carter \& Tager-Flusberg, 2008, Bryson, 1996).

Autism spectrum disorders occur throughout all socioeconomic groups, and current statistics indicate it affects 1 out of 91 eight-year-old children in the United States (Kogan et al, 2009). Boys are four times more likely to be diagnosed with autism than girls. With the increase in awareness of autism spectrum disorders among health practitioners, children are often routinely diagnosed as early as 18months-old.

The cause and treatment of autism is currently under debate. Researchers feel there may be a combination of genetics and environmental factors (CDC, 2009). Many treatments have been attempted in the process of some form of recovery, including biomedical interventions, physical and occupational therapies, speechlanguage therapies and behavior and developmental interventions (Ospina et al, 2008).

Researchers have a much better understanding of language development and nonverbal communication in autism (Lord, 2000). The studies concerning autism and communication problems have relied on small numbers of participants. This has created some mistrust of the validity of such studies; however, the effectiveness of certain techniques to intervene and facilitate communication has been 
documented, such as applied behavior analysis (ABA), Picture Exchange Communication System (PECS) and a variety of transactional, developmental and complementary approaches (Landa, 2007).

Individuals who work in the equine assisted activities and therapies fields have often witnessed the power of the horse to positively influence communication skills in children with disabilities, including those that have been nonverbal. There are many stories from NARHA center personnel about nonverbal riders saying their first word while riding a horse. However, as with all stories, unless these events are formally assessed and noted, they remain nothing more than tales of success, without the data to back up these claims.

There are two distinct issues here: the ability of the horse to communicate and interact with humans, and the inability of many of those children with autism disorder to communicate and interact with other people. The blending of these two issues creates a unique situation of using the horse as a form of therapy for those diagnosed with autism disorder. This leads to stating the obvious - the earlier that a child diagnosed with autism disorder can begin any type of therapy or intervention the better. Because of the positive perceptions reported by NARHA center personnel, as well as the positive results of some recent studies (Bass, Duchowny, \& Liabre, 2009) using equine assisted activities and therapies for children with autism should be strongly considered by parents and caretakers.

\section{Previous Research}

Parents of children with autism are faced with a multitude of treatment options to try and help their children. Some are quite valid, but many others have 
been found to be a waste of time and money (Hanson et al, 2007). Therapeutic riding has been found to be a useful intervention in the treatment of autism by therapeutic riding instructors and the participants' families, but much of perception of benefit to the rider with autism is anecdotal, and in the form of testimonials. Another equine-related treatment option that has gained much attention in recent years for autism is hippotherapy, an equine therapy that uses the horse and its movements by occupational, physical or speech therapists in their treatment plan for their patients. The medical community regards hippotherapy as an alternative therapy method. However, in one major study, $74 \%$ of 112 families with a child with autism used complementary and alternative forms of therapy (Hanson et al, 2006). Hippotherapy is ideal when used as an early intervention, as the specialists using hippotherapy can begin treating children as early as 2-years-old.

Horseback riding has been used in a positive manner for many types of disabilities for centuries. Because of the limitations of time and resources, research has been limited in scope and manner. The last few years have produced the greatest push for the need to "prove" that equine assisted activities and therapies really work. Most of the research that has been published over the years has shown overwhelming positive benefits of the physical and emotional interactions with horses (American Hippotherapy Association, 2009).

The limited amount of research that has been done in the field of hippotherapy has highlighted many positive benefits. Improvement in gross motor function (Sterba, Rogers, France, \& Vokes, 2002) sensory integration (Gewurtz \& Eccles, 2007), and improvements in diseases such as multiple sclerosis (Hammer et 
al, 2005) are among many other positive benefits of using a horse for therapy. The favorable impact that the horse and its movement has on all aspects of postural support and cortical organization gives the participants the chance to more efficiently use their cognitive and language abilities (Dismuke-Blakely, 1997).

Autism spectrum disorder creates impairments and delays with language, social and motor skills and behavior. Researchers need to build upon those studies that involved other disorders and/or diseases and focus on hippotherapy to help treat autism (Stoner, 2007). Research has also been limited to older children (McCauley \& Gutierrez, 2004) and with the advances in the early diagnosis of autism, it brings up the importance of early intervention (Autism Research Institute, 2008).

Early intervention is imperative because it helps with the developmental aspects of language (Thurm, Lord, Lee \& Newschaffer, 2006). Several types of therapies have shown to be of tremendous help to children with autism in their critical development phases (Adams, Edelson, Grandin, \& Rimland, 2008). Understanding the characteristics of language and its early development is important for educators and their use of intervention therapies (Philofsky, Fidler, \& Hepburn, 2007).

Research is ongoing to understand when the time is optimal for communicative and social development, where the settings should occur, what types of interventions are working for those children with autism (Koegel et al, 2000). Communicative isolation is a problem with children with autism, and social 
interactions are key to gaining any type of competence in verbal or nonverbal communication skills.

Children involved in a study by Sams, Fortney \& Willenbring (2006) showed significant positive changes in the use of language and social interaction when involved in therapy sessions involving animals. Occupational therapists designed and performed therapy sessions with the participants, which involved interactions with a variety of different types of animals, including dogs, rabbits and llamas. Standard occupational therapy sessions were compared with occupational therapy sessions with animals by using rating forms designed by the researchers. These forms were divided by language use and social interaction criteria. Verbal and nonverbal children with autism were in the study, and communication attempts by the subjects were divided into "spontaneous" and "prompted", with consideration for meaningful use of any type of communication. Results showed positive significance in the Use of Language and the Social Interaction rating scales, as compared to the standard occupational therapy sessions. Researchers concluded although it may not be feasible to utilize animals in standard occupational therapy practices, using animals is quite effective in motivating and enhancing responses for speech and language development in children with autism.

Although a study by Mccauley \& Gutierrez (2004) did not focus specifically on autism, it did show that hippotherapy was successful with children with language-learning disabilities. Three boys under the age of 12 with diagnosed speech and language difficulties were enrolled in a hippotherapy program. Questionnaires developed by the researchers were given before the therapy and 
after. Speech-language pathologists conducted the hippotherapy sessions, and activities while the subjects were riding were adapted from traditional therapy sessions. Researchers used the questionnaire to assess whether subjects improved in speech and language abilities, motivation, self-concept, and the effectiveness of hippotherapy versus traditional therapy. Parents of the participants felt that hippotherapy was more effective than traditional therapy on all assessed comparisons. Parents also reported that these improvements carried over the participants' everyday lives, and felt that the children were not even aware that they were in therapy, as it turned into an enjoyable experience that highly motivated their attendance to the sessions.

A study by Bass et al (2009) required teaming up with Good Hope Equestrian Training Center, a NARHA Premier Accredited facility, and participants from the Agency of Persons with Disabilities and from the University of Miami's Center for Autism Related Disabilities. As the most significant and specific study to date involving participants with autism and equine assisted activities and therapies, the study focused on the effects of therapeutic riding on social functioning in children with autism. The study was partially funded by the Horses and Humans Research Foundation, which was formed in 2002 solely to financially support studies that would determine the value of equine assisted activities and therapies (Horses and Humans Research Foundation, 2008). The Good Hope team had previously conducted a pilot study that involved 33 riders, and found statistical significance in four of the subscales tested: sensory seeking, attention and distractibility, sensory sensitivity and sedentary measurements. A 12-week therapeutic riding session was 
conducted with 34 four to ten year old participants, half which participated in the riding sessions, and the other half remained on a wait list for riding services. Pretest and post-test assessments were conducted using the questionnaire based Social Responsiveness Scale (SRS) and the Sensory Profile. Riding sessions were conducted in the typical manner of a NARHA based therapeutic riding lesson, including exercises, teaching of riding skills, and mounted games and horsemanship activities. Subscale data from the Sensory Responsiveness Scale on interactions between group and time effects for sensory seeking, attention and disability, sensory sensitivity and sedentary all showed significant positive changes versus the control group. The fine motor/perceptual subscale had no significance. Social motivation on the Sensory Profile had a significant group $\mathrm{x}$ time interaction as well, although no significant interactions were present for the subscales social cognition or social awareness.

Researchers concluded that the increase in social functioning could be linked to the stimulation of the horse, either through the movement of the horse or the physical presence of being around the horse. A hallmark trait of autism is the desire for routine and repetition. The riding sessions represent a remarkable deviation from this as interaction with the horse and the activities involved may create a unique stimulus, which results in positive changes with engagement. Researchers also linked the possibility of improvement in cerebellar functioning because of the involvement of motor learning skills and motor control. Researchers suggested that future studies include more comprehensive assessment by increasing the number and length of the sessions. 


\section{Personnel involved in Equine Assisted Activities and Therapies}

Therapeutic riding instructors certified through NARHA are required to develop a good working knowledge of disabilities. Individuals with autism disorder have characteristics that the movement of the horse seems to address, including the stimulation of the sensory and vestibular systems. Selecting the right equipment for the individual rider is important, as is the ability to match a horse's gait with the needs of the individual with autism disorder.

Occupational therapists, physical therapists and speech-language pathologists who use hippotherapy take special workshops and certifications to increase their awareness and needs of their clients with disabilities. Since they only apply the movement of the horse as a tool for therapy, often a therapeutic riding instructor and/or experienced horse handler is part of the therapeutic team for a hippotherapy session. Volunteers are utilized in the hippotherapy program, as well as the therapeutic riding program. For those children with a diagnosis of autism disorder, these therapy or riding sessions can be a vital aspect of developing socialization skills. Many of the professionals and volunteers develop positive relationships with participants with autism, and may help contribute to promoting cognitive flexibility, or the ability to react to different situations (Geurts, Corbett, \& Solomon, 2009).

Other types of equine specialists are involved with Equine Facilitated Mental Health fields, which include equine facilitated learning (EFL) and equine facilitated psychotherapy (EFP). These fields combine a mental health care professional (counselor, psychotherapist, social worker or psychiatrist), and an equine with a 
patient or client with a mental health challenge (EFMHA, 2008). EFMHA, as a subspecialty of NARHA, has been developed just as the increase of participants with emotional and behavioral needs has risen by 10 percent. Many of those with autism disorder have corresponding behavioral issues, which, depending on the age of the participant, can be addressed through an equine facilitated psychotherapy or equine facilitated learning program as well as a therapeutic riding program.

\section{How Does the Horse Affect Communication of a Rider with Autism?}

The three-dimensional gait and movement of the horse's stride and the multi-faceted stimuli from this motion is imparted to the rider (Bertoti, 1988). These stimuli affect and help normalize the sensory-motor systems, which in turn can help give the nervous system the ability to improve the cognitive and language responses of a rider, including those with autism (Macauley \& Gutierrez, 2004). King (2007) produced a study that showed the improvement of verbalization, verbal organization and increased attention and focus on 12 four to ten year old children with autism.

A study by Taylor et al (2007) reported measurable improvement in motivation from hippotherapy with children with autism. The motivation of responding to a verbal prompt, or what is known as orienting cues, (Koegel et al, 2009) can be used by trained personnel to encourage the rider with autism to ask the horse to "walk-on" (go) or "whoa" (stop). This simple routine often elicits the first attempts at verbalization, or at the very least, an attempt at a communicative gesture. 
Trunk muscles and control of the diaphragm, physical attributes that are necessary for speech, are improved just from sitting astride the horse while walking (Borton \& Ogburn, 2009). The environment of the rider (such as being astride a horse outside on a sunny day) brings a different perspective to the lives of participants with autism in equine assisted activities and therapies that may not have much opportunity to be in contact with animals, particularly in this context. Mancil, Conroy \& Haydon (2008) produced a study that determined that milieu therapy intervention (teaching children communication skills in a natural environment) for those with autism increased unprompted communication. The natural environment is the child's home, school or activity where a child spends time, in contrast to a typical clinical setting for speech and language therapy. An equine assisted activities and therapies center is potentially the ideal environment for facilitating improvement in communication skills.

Dr. Temple Grandin, a professor of Animal Science at Colorado State University has written several books and many articles on her experiences as a person with autism. In the best-selling book, "Animals in Translation", she relates the relationship she had with horses in her youth to her success in adulthood (Grandin \& Johnson, 2005). Through her gifts as an author, professor and lecturer, Dr. Grandin has been an important contributor to societal understanding of the complexities of the communication deficits and behaviors of people with autism. 


\section{The Intervention Format of A Equine Assisted Activities and Therapies}

\section{Session}

A therapeutic riding lesson and/or a hippotherapy session for a new participant or client would follow much the same format. Instructors and/or therapists involved with the session would have a thorough understanding of the participant's range of issues pertaining to their disability. For participants with autism, the elements of the session, including goals and objectives would be based on parent/caretaker information, medical evaluation by a physician, and observation by the instructor and/or therapist. Understanding of facilitating communication is key when working with the participant, because the interaction between participant and horse, and participant and instructor/therapist will be the foundation of trying to begin the intervention process.

Whether the participant is two or twenty, the process is the same. The horse will be the true motivator and provider of stimulation, but the instructor/therapist needs to have the experience and training to try and elicit the beginnings of a relationship between themselves and the participant.

Many children with autism involved in NARHA programs have sensoryintegration and behavioral issues and require structure and routine to cope with these behaviors (Pavlides, 2008). NARHA center personnel that serve participants with autism, whether through hippotherapy, therapeutic riding or equine facilitated learning all understand the need to address these issues by the logical sequencing and organization of their sessions. 
Most NARHA registered therapeutic riding instructors structure their lessons based on the distinct organizational pattern as advocated in instructor training. This includes writing goals and objectives for the individual participant, and planning the session out in detail ahead of time. Also specified are the selection of the horse, tack and/or specialized equipment the participant needs, volunteers needed to assist with the lesson, and the precise details of what will be taught to the participant in the session. This may include warm-up, review of last session skills, introduction of new skills, games based on skills learned and a cool-down period. In reference to the variety of issues being presented by the participant with autism disorder, the instructor must be aware of any behavioral, cognitive or physical problems that the participant may have.

Occupational therapists, physical therapists and speech-language pathologists proceed with a riding session using the horse as part of the treatment plan for the patient. These types of rehabilitation specialists use the horse's movement to facilitate treatment. For certain types of patients, horse riding is considered the ideal method of therapy (Funk \& Smith, 2000).

Often NARHA or hippotherapy programs will incorporate aspects of current best practices for working with children with autism. This includes using augmentative and alternative communication devices (AAC), which some fear would impede the development of language. However, current research shows no evidence that using augmentative or alternative communication devices disrupts the development of language (Schlosser \& Wendt, 2007). 
Applied Behavior Analysis (ABA) is a treatment used for intensive behavioral intervention (Grindle, Kovshoff, Hastings, \& Remington, 2009) for autism. ABA in its traditional sense is used to develop skills based on task analysis through antecedent-behavior-consequence sequencing. The ABA traditional approach focused on non-distracting surroundings with all tasks initiated by adults. The more contemporary approach using the ABA principle is focusing on the child's participation in the treatment as a partner, using natural environments and facilitating communication methods based on child selected activities. The goal with the modern ABA approach is spontaneous communication using the child's own motivation (Landa, 2007). DIR/Floortime is another popular intervention method based on sensory stimulation, visual input and motor planning. (The Interdisciplinary Council On Developmental And Learning Disorders, 2009). There are a multitude of variations on these interventions, all with the goal of increasing developmental abilities in a natural environment. Equine assisted activities and therapies for children with autism seems to be a perfect fit for utilizing some of these proven intervention methods in conjunction with their riding sessions.

The Picture Exchange Communication System (PECS), which is used by many families to communicate with their children with autism disorder, is sometimes incorporated into the structure of the therapeutic session. PECS is a picture-based system of communication that allows the individual with little or no speech to indicate what they want by exchanging a picture or symbol of their desire (Preston \& Carter, 2009). Therapists or riding instructors often have a "horse" version of the 
PECS system to use when they are preparing to go to the NARHA center and/or when they are asked to perform tasks while riding.

\section{The Need for Education for Equine Assisted Activities and Therapies Professionals}

Equine assisted activities and therapies professionals serve a wide array of different types of disabilities. In order to understand these disabilities and how to serve them appropriately in a riding session, NARHA recently developed a higher education membership for colleges and universities to help provide certification guidelines for students desiring to study equine assisted activities and therapies. NARHA registered therapeutic riding instructors come from a wide variety of backgrounds. Some individuals have good equine skills, while others have strong special education or disability studies backgrounds. Currently, NARHA registered instructors are not required to have an academic degree. NARHA has recognized the need to produce registered riding instructors with academic backgrounds, and this new membership will assist colleges and universities in their goals of meeting student demand for increasing equine assisted activities and therapies as part of their service-based learning curriculum (Brady et al, 2005). The growth in involvement of colleges and universities with curricula will potentially go hand-inhand with the push for research in the equine assisted activities and therapies field. The American Hippotherapy Association has developed workshops for treatment principles and equine skills education for physical therapists, occupational therapists and speech language pathologists. Specific workshops for sensory 
problems and communication disorders, such as those found in children with autism, are offered by American Hippotherapy Association faculty (AHA, 2010).

\section{Funded Intervention Programs}

Parents of children have many better options for help with early intervention methods than they had less than ten years ago, but they still have many difficulties in locating help and services. The federal grant-based Early Intervention Program serves ages birth through three, but after age three the parents are forced to seek help from other sources, which can be dependent on location and availability. The public school systems have early education programs that may help, and there are learning centers that focus on autism that are available in certain areas. Parents of children with autism in this pre-kindergarten age group are forced to seek out resources and help on their own, and there is rarely financial help available for intervention treatments. These out-of-the pocket costs are prohibitive for many parents. This is one reason that many equine assisted activities and therapies centers keep their rates low. Many centers offer therapeutic riding sessions for as little as $\$ 10.00$ per ride, but this cost varies depending on location and services.

The Early Intervention Program for Infants and Toddlers is a federal program that is a section (Part C) of the Individuals with Disabilities Education Act (IDEA). The program, developed in 1990, distributes grants to states in helping them establish early intervention services from birth to age three. Although voluntary, all 50 states have a program in place, but implementation of part $\mathrm{C}$ of IDEA varies in practice, as states are allowed some discretion in eligibility of participants. IDEA part C programs generally provide support and services to those 
children with developmental delays, as well as risk of delay. Children with cognitive, physical, social/emotional, adaptive and communication delays are all entitled to receive services from professionals who can identify and provide intervention services. A child with a diagnosis of autism is normally eligible for services under Part $\mathrm{C}$ because of their delays with communication, cognitive and social/emotional skills. A survey of the Part C programs indicated that states handled the implementation of services for children with autism in a variety of ways (Stahmer \& Mandell, 2006). This survey indicated that the majority of states did not have guidelines for specific interventions for children with autism, therefore, the individual agencies implementing the programs within the state were developing the treatment plans. This type of independence most likely has allowed some freedom for clinicians providing services for programs under Part $\mathrm{C}$ to providing treatment services such as hippotherapy. Children three through age 21 with disabilities may then be eligible for services under part B of IDEA, which are provided through the public education systems under special education guidelines.

A good example of a hippotherapy program that fully embraces the concept of the IDEA program is Ironstone Farm of Massachusetts. Ironstone Farm provides a service called Ironstone Therapy, based on the early intervention model dictated by part B of IDEA, and provides hippotherapy to those as young as nine months old through the use of occupational therapists, physical therapists and speech-language pathologists. The Department of Public Health of Massachusetts has approved these hippotherapy services since 2001. 


\section{Costs}

Medical insurance normally does not cover equine assisted activities and therapies. This is part of the reason for the need for research and public education, so that equine assisted activities and therapies can be funded and reimbursed, therefore, making them much more accessible to those that could benefit from them (Horses \& Humans Research Foundation, 2008). Physical therapists, occupational therapists, and speech language pathology professionals find ways to gain insurance approval for their services under hippotherapy. Often the insurance is coded and billed as traditional therapy, without the detail of the horse's involvement in the treatment. Unless hippotherapy and therapeutic riding become an evidence-based practice for treatment or invention for autism, the lack of adequate medical reimbursement remains an issue with current and potential participants. The involvement of the state-run early intervention programs under IDEA Part C has somewhat changed the financial picture for identified children, but those programs are experiencing funding issues. Many states are implementing cost reduction strategies for their IDEA Part C programs (Grant, 2005), so the NARHA centers involved with Part C funding are in jeopardy of losing those reimbursements.

\section{The Need for Assessment}

Professionals involved in equine assisted activities, including registered therapeutic riding instructors, or those specifically using hippotherapy, have a need to keep good records on the progress of their participants.

The field of therapeutic riding, although instructors are trained to maintain progress reports and assessments, does not have a standardized method of keeping 
records that lends itself to measuring outcomes. Research is difficult even in the professional mode of the hippotherapy world, as physical therapists, occupational therapist and speech language pathologists are trained to do assessments of functional outcomes. Unfortunately, the nature of hippotherapy and its one-on-one client sessions does not easily create large sample sizes for research (Hubbard, 2007).

With the lack of research hindering the equine assisted activities and therapies fields, any attempt at measuring outcomes, particularly in the assessment of changes in participants of EAAT with autism disorder, is highly welcome.

\section{Survey Results}

A survey was sent by email in March of 2009 to 225 NARHA Premier Accredited Centers regarding the use of assessments and/or measurement outcomes in their programs. A list of NARHA Premier Accredited Centers was obtained from a center membership list on the NARHA website. Premier Accredited NARHA centers have an elite standing among the almost 800 NARHA centers nationwide because they have passed an on-site review by NARHA evaluators for the centers' strict adherence to NARHA standards. The NARHA Premier Accredited membership list included email addresses for contact. Five questions were sent by email to each NARHA Premier Accredited Center, two of which related to measurement outcomes and autism.

1. Explain how your NARHA center measures the outcomes or progress of riders/participants in your therapeutic riding program? If you have a copy of any 
forms you use and would be interested in sharing with this project, it would be greatly appreciated.

2. If you do special assessments or measurements of outcomes or progress for riders/participants with autism (other than what you provided in question 1, please share those forms as well.

Approximately 12\% (27) of the surveys were returned (see Table 1). 7\% of surveyed centers used a separate form of assessment specifically for children with autism. One center representative stated they used a separate form for children with autism, the "Autism Treatment Evaluation Checklist" (ATEC), developed by Dr. Bernard Rimland (Autism Research Institute, 2009). This form covers speech/language or communication skills, social skills, sensory/cognitive awareness and health/physical behaviors.

The majority of NARHA centers (44\%) that responded to the survey used only written observations for goals and objectives for all of their participants. This is the method of record keeping that NARHA workshops train therapeutic riding instructors to use for the structure of riding lessons and keeping progress notes. A general form for all participants that contained checklists or scoring methods of assessments, but with no communication skills specified, was utilized by $33 \%$ of the reporting centers. Another 7\% used parent and/or teacher feedback, with no written assessments at all.

In reviewing the variety of forms used for assessments by the centers, it became clear that some individual centers had developed formats to include the characteristics or symptoms of autism, including speech/language, sensory 
integration, perceptual skills and attention/focus, so it was understandable that additional types of rider assessments may have been perceived as unnecessary. NARHA centers serve such a wide variety of disabilities that many of the forms often seemed to attempt to cover as many types of assessments as possible.

\section{Conclusions}

Equine assisted activities and therapies are currently being used as an early intervention with success in children with autism who have communication disorders. Although much of the evidence of this "success" is anecdotal, there is a continuation of efforts by equine assisted activities and therapies centers to provide this type of intervention treatment to children with autism. Parents and caretaker also see the positive results of equine-based interventions on the speech and communication of children with autism, and the demand for this type of service is high, evidenced by the large number of children on wait-lists (NARHA, 2010).

Survey results indicated most centers that responded had little or no means of assessing children with autism. Forms from centers indicated a wide variety of methods of assessing riding skills and mobility. The substance and quality of these forms were dependent on the center's needs and the interests, abilities and training of center personnel. There is a real need to emphasize the importance of including a communication assessment for children with autism, and the hope is that some type of guidance will come from NARHA and the AHA to help all centers develop a standardized method of record keeping on the progress of improving riders' communication deficits. This may prove to be very difficult because of the variation in the abilities and performance of children with autism. 
Since autism is one of the main disabilities served by NARHA centers, it would make sense to focus on the specific needs of those with autism, instead of attempting to make one type of assessment format fit all types of riders. Written progress notes are important, but an assessment form or computer based program that allows progress to be numerically rated and then compared and contrasted with previous assessments, either on a monthly or bimonthly basis, would be essential. Information from parents and caretakers should be recorded periodically to detail the progress of communication skills that are demonstrated at home. This is important in determining whether the communication skills acquired from the equine assisted activities and therapies program are being transferred into practical, everyday use by the child with autism disorder.

The author of this paper developed a measurement outcome form (Appendix A) for use with participants with autism in therapeutic riding programs based on the Autism Research Institute's checklist for autism symptoms (Autism Research Institute, 2009). This form can be used for evaluating and applying scores to specific categories, such as eye contact, using numerical values of 1, 2 and 3 . Numbers can be totaled in each grouping (speech/language/communication, sociability, sensory/cognitive) to show statistical changes in behavior characteristics specific to autism. Participants with autism can also be evaluated with the form developed by the author to use for evaluating and scoring riding skills, as seen in Appendix C.

In the ideal scenario, all information produced should go directly into a computer or handheld device for ease in tracking and producing statistical trends. A new software program was released in October of 2010 that may hold great promise 
for a tool to electronically record information about progress of a participant with autism. The company, Handhold Adaptive, claims their software product, AutismTrack, will show patterns and trends of behavior of people with autism based on specific intervention methods (Handhold Adaptive, 2010). Although the usefulness of this product remains to be seen for equine assisted activities and therapies, it appears to be a significant way to collect and analyze data easily through the use of a handheld device.

NARHA and the AHA also need to emphasize the proper training and knowledge base for their certified instructors and hippotherapy specialists. The epidemic of autism is a very real societal concern, and those involved in equine assisted activities and therapies can play an important role in early intervention methods for their participants with autism. It is imperative that the professionals involved in equine assisted activities and therapies understand the disabilities with which they work. Renker (1993) surveyed NARHA therapeutic riding evaluators (those who certify therapeutic riding instructors). The evaluators felt that the instructors needed to improve their skills and, therefore, their effectiveness, which included knowledge of disabilities. NARHA and the AHA should develop in-depth educational materials that will help these professionals understand the current best practices for working with children with autism. Without a true understanding of the specific symptoms and effective treatments and teaching strategies for children with autism, equine assisted activities and therapy specialists will not be able to adequately serve this population. 
As with any disability that involves cognitive and sensory issues, the process in assessing or measuring the progress or improvements of those individuals within the autism spectrum by researchers remains difficult. Researchers struggle with agreeing on effective evaluation instruments, particularly in the equine assisted activities and therapies field. Serious research efforts on the effects of equine assisted activities and therapies on individuals with autism should continue, with the use of studies with larger sample sizes, perhaps from multiple NARHA centers, followed over longer periods of time. The use of single case research should not be dismissed, as this type of research format is a reasonable option for the smaller NARHA centers. Researchers should focus on what is important to families and caretakers of children with autism - improving their children's abilities with communication and social functioning. These studies should yield the type of results that will validate what has mostly been perceived to be a positive intervention treatment for communication disorders in children with autism. The information concerning the effectiveness of equine assisted activities and therapies for children with autism can then be disseminated and promoted to the appropriate health care and intervention program specialists.

Families and caretakers of children with autism face many challenges, including wandering through the maze of interventional treatment strategies to that may help their children. Equine assisted activities and therapies can be an important part of those treatment choices. The field of equine assisted activities and therapies offers, with the simple use of horses, an amazing opportunity to make a difference in the lives of the children with autism. 
Table 1.

Communication assessments for autism from survey of NARHA Centers

Type of Assessment

Format

$\%$

Separate form for autism

Checklist

$7 \%$

Non-specific form for all

Checklist

disabilities

No communication skills specified

General form containing subsections

Checklist

for communication skills

(receptive language, expressive language)

Specific terms for communication

Checklist

(sign language, gestures, symbols, facial expressions, eye gaze)

Verbal parent/teacher feedback

$\mathrm{N} / \mathrm{A}$

$7 \%$

for communication skills

No written assessments

Written observations for goals/objectives

No communication skills specified

Written

$44 \%$ 
Table 2. Premier Accredited NARHA Center survey

1. Explain how your NARHA center measures the outcomes or progress of participants in your therapeutic riding program? If you have a copy of any forms you use and would be interested in sharing with this project, it would be greatly appreciated.

2. If you do special assessments or measurements of outcomes or progress with riders/participants with autism (other than what you provided in question 1), please share those forms as well. 


\section{References}

Adams, J., Edelson, S., Grandin, T., \& Rimland, B. (2008). Advice for parents of young autistic children. Retrieved from http://www.autism.com/index.asp

American Hippotherapy Association (2009). Retrieved March 3, 2009, from http://www. americanhippotherapyassociation.org/

American Psychiatric Association (2000). Diagnostic and statistical manual of mental disorders (4th ed.). Washington, DC: Author.

Autism Research Institute (2008). Retrieved March 3, 2009 from http://www.autism.com/fam_whatisautism.asp

Autism Research Institute (2009). Diagnostic checklist form e-2 and research questionnaire form e-3. Retrieved from http://www.autism.com/autism/first/e23.htm

Bass, M. M., Duchowny, C. A., \& Liabre, M. M. (2009). The effect of therapeutic horseback riding on social functioning in children with autism. Journal of Autism Developmental Disorders, 39(9), 1261-1267.

Bertoti, D (1988). Effect of therapeutic horseback riding on posture in children with cerebral palsy. Physical Therapy, 68(10), 1505-1512.

Borton, B. B., \& Ogburn, A. C. (2009). Therapeutic riding and hippotherapy: what is it and how does it work? Retrieved from http://www.speechpathology.com/articles/article_detail.asp?article_id=367

Brady, H. A., Lawver, D. E., Guay, K. A., Pyle, A. A, \& Cepica, N. T. (2005). Principles of therapeutic riding as a service-learning course within an agricultural curriculum. NACTA, 49(4), 19-23. 
Brandt, K. (2004). A language of their own: an interactionist approach to humanhorse communication. Society \& Animals, 12(4), 299-316.

Bryson, S. (1996). Brief report: epidemiology of autism. Journal of Autism \& Developmental Disorders, 26(2), 165-167.

CDC (2009). Retrieved April 1, 2010, from

http://www.cdc.gov/ncbddd/autism/index.html

Center For Excellence In Disabilities (2009). Retrieved November 12, 2009, from http://www.cedwvu.org/

Chandler, C. (2003). Sensory intergration and therapeutic riding at summer camp: Occupational performance outcomes. Physical \& Occupational Therapy in Pediatrics, 23(3), 51-64.

Dismuke-Blakely, R. (1997). Hippotherapy as a treatment modality for speech/language therapy. Riding the Wings of Progress Proceedings of the Ninth International Therapuetic Riding Congress, 38, 195-199.

EFMHA (2009). What is EFMHA? Retrieved from http://www.narha.org/SecEFMHA/WhatIsEFMHA.asp

Engel, B. T. (2007). An introduction to hippotherapy terminology and development. In B. Engel \& J. McKinnon (Eds.), Enhancing Human Occupation Through Hippotherapy (1st ed., pp. 3-5). Bethesda: The American Occupational Therapy Association, Inc..

Funk, M. S., \& Smith, B A. (2000). Occupational therapists and therapeutic riding. Anthorozoos, 13(3), 174-180. 
Geurts, H. M., Corbett, B., \& Solomon, M. (2009). The paradox of cognitive flexibility in autism. Trends in Cognitive Science, 13(2), 74-82.

Gewurtz, R., \& Eccles, A. (2007). Use of sensory integration in equine-assisted therapy: an occupational therapy perspective. In B. Engel \& J. MacKinnon (Eds.), Enhancing Human Occupation Through Hippotherapy (1st ed., pp. 8991). Bethesda: The American Occupational Therapy Association, Inc..

Grandin, T, \& Johnson, C (2005). Animals in translation (1st ed.). New York: Scribner.

Grant, R. (2005). State strategies to contain costs in the early intervention program: policy and evidence. Topics in Early Childhood Special Education, 25(4), 243250.

Grindle, C. F., Kovshoff, H., Hastings, R. P., \& Remington, B. (2009). Parent's experiences of home-based applied behavior analysis programs for young children with autism. Journal of Developmental Disorders, 39(1), 42-56.

Hammer, A., Nilsagard, Y., Forsberg, A., Pepa, H., Skargren, E., \& Obeg, B. (2005). Evaluation of therapeutic riding (Sweden) and hippotherapy (United States). A single-subject experimental design replicated in eleven patients with multiple sclerosis. Physiotherapy Theory and Practice, 21(1), 51-77.

Handhold Adaptive (2010). Retrieved September 22, 2010, from http://www.handholdadaptive.com/

Hanson, E., Kalish, L., Bunce, E., Curtis, C., McDaniel, S., Ware, J., et al (2007). Use of complementary and alternative medicine among children diagnosed with autism spectrum disorder. Journal of Autism Developmental Disorders, 37(4), 628-636. 
Hoppe, S. E. (2005). Parent perceptions: communication, interaction, and behavior in autism. Teaching Exceptional Children Plus. Retrieved March 14, 2009, from http://escholarship.bc.edu/education/tecplus/vol1/iss4/5

Horses And Humans Research Foundation (2008). Retrieved May 2, 2009, from http://www.horsesandhumans.org/About_Us.html\#Mission

Horses And Humans Research Foundation (2009). Awarded Projects. Retrieved May 2,2009 , from http://www.horsesandhumans.org/Research AwardedProjects.html

Hubbard, SL. (2007). A chronological and historical review of research related to Hippotherapy. In B. Engel (Ed.), Occupational Therapy: Enhancing Human Occupation Through Hippotherapy. (1 ${ }^{\text {st }}$ ed., pp. 47-69). Bethesda, MD: American Occupational Therapy Association, Inc.

The Interdisciplinary Council On Developmental And Learning Disorders (2009). What's DIR/Floortime? Retrieved May 13, 2009, from http://www.icdl.com/dirFloortime/overview/index.shtmlt

King, Nancy (2007). Perceived efficacy of therapeutic riding for children with autism. In B. Engel \& J. Mackinnon (Eds.), Occupational Therapy: Enchancing Human Occupation Through Hippotherapy (1st ed., pp. 119-126). Bethesda, MD: American Occupational Therapy Association, Inc.

Koegel, R. L., Shirotova, L., \& Koegel, L. K. (2009). Brief report: Using Individualized orienting cues to facilitate first-word acquisition in non-responders with autism. Journal of Autism and Developmental Disorders, 39(11), 1587-1592. 
Kogan, M. D., Blumberg, S. J., Schieve, L. A., Boyle, C. A., Perrin, J. M., Ghandour, R. M., et al (2009). Prevalence of parent-reported diagnosis of autism spectrum disorder among children in the US, 2007. Pediatrics, 124(5), 1395-1403.

Landa, R. (2007). Early communication development and intervention for children with autism. Mental Retardation and Developmental Disabilities Research Reviews, 13(1), $16-25$.

Lord, C. (2000). Commentary: achievements and future direction for intervention research in communication and autism spectrum disorders. Journal of Autism and Developmental Disorders, 30(5), 393-398.

Luyster, R. J., Kadlec, M. B., Carter, A., \& Tager-flusberg, H. (2008). Language assessment and development in toddlers with autism spectrum disorders. Journal of Autism and Developmental Disorders, 38(8), 1426-1438.

Macauley, B. L., \& Gutierrez, K. M. (2004). The effectiveness of hippotherapy for children with language-learning disabilities. Communications Disorders Quarterly, $25(4), 205-217$.

MacKinnon, J. R. (2007). What is the state of hippotherapy research, and where should we go from here? In B. Engel \& J. Mackinnon (Eds.), Enchancing human occupation through hippotherapy (1st ed., pp. 158-173). Bethesda: American Occupational Therapy Associations, Inc..

Maiga, H. A., \& Westrom, L. E. (2006). Integration of service learning in animal science curriculum. NACTA, 50(3), 57-64. 
Mancil, G. R., Conroy, M. A., \& Haydon, T. F. (2009). Effects of a modified milieu therapy intervention on the social communicative behaviors of young children with autism spectrum disorders. Journal of Autism \& Developmental Disorders, 39(1), $149-163$.

McGibbon, N. H., Benda, W., Duncan, B. R., \& Silkwood-Sherer, D. (2009). Immediate and long-term effects of hippotherapy on symmetry of adductor muscle activity and functional ability in children with spastic cerebral palsy. Physical Medicine and Rehabilitation, 90(6), 966-974.

NARHA (2010). Who is NARHA? Retrieved September 12, 2010, from http://www.narha.org/WhoIsNARHA/About.asp

NARHA (2009). NARHA 2009 Fact Sheet. Retrieved September 22, 2009, from http://www.narha.org/PDFfiles/2009NARHAFactSheet.pdf

Ospina, M. B., Seida J. K., Clark, B., Karkhaneh, M., Hartling, L., Tjosvold, L., et al (2008). Systematic reviews of psychosocial interventions for autism: an umbrella review. Developmental Medicine \& Child Neurology, 51(2), 95-104.

Pavlides, M. (2008). Animal-assisted interventions for individuals with autism (1st ed.). Philadephia: Jessica Kingsley.

Philofsky, A., Fidler, D. J., \& Hepburn, S. (2007). Pragmatic language profiles of schoolage children with autism spectrum disorders and Williams syndrome. American Journal of Speech-Language Pathology, 16, 368-380.

Preston, D., \& Carter, M. (2009). A review of the efficacy of the picture exchange communication system intervention. Journal of Autism \& Developmental Disorders, 39(10), 1471-1486. 
Renker, L. (1993, November). The process of teaching therapeutic horseback riding. Paper presented at the meeting of the Annual Conference of the North American Riding for the Handicapped Association. Lexington, KY.

Sams, M. J., Fortney, E. V., \& Willenbring, S. (2006). Occupational therapy incorporating animals for children with autism: a pilot investigation. American Occupational Therapy Association, 60, 268-274.

Schlosser, R. W., \& Wendt, O. (2008). Effects of augmentative and alternate communication intervention on speech production in children with autism: a systematic review. American Journal of Speech-Language Pathology, 17(3), 212-230.

Stahmer, A. C., \& Mandell, D. S. (2007). State infant/toddler program policies for eligibility and services provision for young children with autism. Administration and Policy in Mental Health and Mental Health Services Research, 34, 29-37.

Sterba, J.A., Rogers, B.T., France, A.P. \& Vokes, D.A. (2002). Horseback riding in children with cerebral palsy: effect on gross motor function. Developmental Medicine \& Child Neurology, 44: 301-308.

Stoner, J. (2007). Efficacy of hippotherapy as a treatment strategy for children with autism. In B. Engel \& J. MacKinnon (Eds.), Human occupation through hippotherapy (1st ed., pp. 119-126). Bethesda: The American Occupational Therapy Association.

Taylor, R. R., Kielhofner, G., Smith, C., Butler, S., Cahill, S. M., Ciukaj, M. D., et al (2009). Volitional change in children with autism: a single-case design study of the impact of hippotherapy on motivation. Occupational Therapy in Mental Health, 25(2), 192-200. 
Thurm, A., Lord, C., Lee, L., \& Newschaffer, C. (2007). Predictors of language acquisition in preschool children with autism spectrum disorder. Journal of Autism and Developmental Disorders, 37(9), 1721-1734.

Whitaker, P. (2007). Provision for youngsters with autistic spectrum disorders in mainstream schools: what parents say - and what parents want. British Journal of Special Education, 34(31), 170-178. 
CHAPTER 2: ESSAY 2

College Curricula for Equine Assisted Activities and Therapies (EAAT)

\author{
Carol C. Petitto \\ West Virginia University \\ Davis College of Agriculture, Natural Resources and Design
}




\section{College Curricula for Equine Assisted Activities and Therapies (EAAT)}

Olivia's* laughter can be heard clear across the ring as she guides her horse Mick over the small bridge that is part of the ring set-up for her weekly riding lesson. West Virginia University students Jon and Gracie both break into smiles as they walk steadily beside Olivia, both with "hand over the thigh" positions to help Olivia maintain her balance. Another student, Liz, has her attention totally devoted to leading Mick and watching him carefully for any changes in mood or attitude. Sara, who is standing in the middle of the ring, is prompting and directing Olivia's progress through the trail obstacles under the watchful guidance of a NARHA registered therapeutic riding instructor. This group of four students has spent many weeks planning this lesson as a team, and today is the culmination of their careful plans. Olivia has neurofibromatosis, epilepsy and developmental delays. The students were required to understand her myriad of disabilities, select a horse that would best fit her needs for the riding lesson, and then carefully carry through an entire thirty-minute lesson based on the natural progression of her independent riding skills.

This scene is replayed at an increasing number of colleges and universities across the country, as the interest and demand grows for classes and internships in college curricula based on equine assisted activity and therapies (EAAT). There are currently over 30 colleges and universities offering some type of curricula for equine assisted activities and therapies.

*Names and identifying references have been changed to protect confidentiality 
In this paper we will explore why equine assisted activities and therapies are important for recreational and therapeutic purposes, and how colleges and universities can play an important part in the education of an EAAT professional. Several considerations for colleges and universities curricula will be examined, including the potential for research funding, service learning opportunities and the expansion of college and university offerings through online courses. A survey was sent to 225 NARHA Premier Accredited Centers to determine what type of relationship they have with a college or university, including partnerships, internships, facilities use or as research collaborators. We will examine what these relationships are, and make some suggestions for furthering these relationships through college curricula development for equine assisted activities and therapies professionals.

\section{What are Equine Assisted Activities and Therapies?}

Equine Assisted Activities and Therapies (EAAT) is an umbrella term for a range of programs derived from working with horses and those with disabilities (NARHA, 2009). The services provided through EAAT include therapeutic horsemanship, hippotherapy, interactive vaulting, therapeutic driving and equine facilitated mental health activities (which include equine facilitated learning and equine facilitative psychotherapy) (NARHA, 2009).

Therapeutic horsemanship involves equine-based activities and programs for people with disabilities, and includes learning riding skills as well as ground activities. The North American Riding for the Handicapped Association (NARHA) is the international association that oversees the certification of therapeutic riding 
instructors who teach in these programs. NARHA also has a member center program, in which centers can maintain regular center memberships, or become Premier Accredited Centers by using on-site reviews of their programs (NARHA, 2009).

Hippotherapy is often provided to children with disabilities as early as 2years-old as a means of early intervention to promote functional outcomes (American Hippotherapy Association, 2009). The American Hippotherapy Association promotes standards of practice for occupational therapists, physical therapists and speech-language pathologists to use the horse and the benefits of its movements to treat their patients. These therapy specialists are part of a team that consists of a horse handler, side walkers, the patient and the therapist. Hippotherapy is different from therapeutic horsemanship in that the horse's movement is a treatment strategy specifically for neuromusculoskeletal dysfunction. Therapy specialists incorporate hippotherapy as part of a total treatment plan, but unlike traditional therapy, it can truly motivate and engage a patient (Benda, McGibbon, \& Grant, 2003). Patients involved in hippotherapy programs can continue on into therapeutic riding at the age of four if the patient is ready for structured riding lessons. Often hippotherapy programs and their corresponding specialists are part of a NARHA center's programming, as the American Hippotherapy Association is an Affiliate Partner of NARHA.

EFMHA, or the Equine Facilitated Mental Health Association (EFMHA, 2009) was a subsection of NARHA programming that has integrated its board of directors and membership with NARHA in November of 2010. NARHA has standards for 
professionals working with equine facilitated learning programs (ELP) and equine facilitated psychotherapy programs (EFP). Mental health professionals use ELP programming as an educational tool to help clients experience the benefits of the horse and human interaction, and helps patients explore their behaviors and feelings (Ewing, MacDonald, Taylor, \& Bowers, 2007). Other mental health professionals choose to practice experiential psychotherapy (EFP) as part of their practice, and this can involve both equine activities on the ground and in the saddle (Lentini \& Knox, 2008). Currently, 185 out of almost 800 centers internationally include ELP or EFP in their programming.

Therapeutic driving and interactive vaulting are both part of equine assisted activities, and both have certifications for instructors in these specialties. Therapeutic driving includes activities related to carriage driving for those with disabilities (Bender \& McKenzie, 2007). Interactive therapeutic vaulting involves horsemanship and movements activities that are based on gymnastic movements while the horse is walking, trotting or cantering (Wiger \& Moore, 2007).

\section{Why Use the Horse?}

Research has shown the value of using equine assisted activities and therapies by demonstrating improvements in a variety of types of disabilities (Hubbard, 2007; All \& Loving, 1999; Pauw, 2000). Although research has been easier to do on the types of disabilities that can be measured in quantitative ways, such as cerebral palsy, some studies have been done with cognitive, emotional and sensory issues, as well the recent interest in research involving equine assisted 
activities and therapies and autism (Bass, Duchowny, \& Liabre, 2009; Taylor et al, 2009).

The initial interest and practical application in the use of the horse for therapy was based on the fact that the movement of the horse is almost an exact imitation of the human walk (Fleck, 1997). The horse has the same sequence of stride as a human. The lateral tilt of the pelvis and the direction of displacement of the walking motion are the same for a human whether actually walking or riding. This direct type of motion and sensation cannot be duplicated in a typical physical or occupational therapy setting.

Humans are also uniquely attracted to horses. Developing this human and horse relationship has proven to be of great benefit in a number of emotional and cognitively based disabilities. Those with psychiatric disabilities have improved their self-esteem (Bizub, Joy \& Davidson, 2003). Yorke, Adams \& Coady (2008) studied subjects that were recovering from some type of trauma, (including car accidents, abuse and chronic disease). Study participants experience significant healing from their trauma from their involvement in a horseback riding program. Others with sensory disabilities, such as autism, have demonstrated positive changes in occupational performance within the context of therapeutic riding (Chandler, 2003).

\section{Professionals Involved with Equine Assisted Activities}

The professionals trained to provide equine-related services to people with disabilities vary widely. Therapeutic riding, driving and vaulting instructors are certified through NARHA, and have to complete a series of written tests, equine 
skills and teaching examinations in order to be able to teach riding, driving or vaulting skills to those with disabilities. For example, candidates for NARHA therapeutic riding certification must be proficient in equine management, horsemanship, riding, instruction, teaching methodology and thoroughly understand disabilities and how they relate to therapeutic horsemanship. After becoming certified, therapeutic riding instructors must accrue twenty hours of continuing education in order to maintain their certification with NARHA.

Professionals with physical therapy, occupational therapy and speechlanguage pathology training and licensure can train through the American Hippotherapy Association to work within the specialty of hippotherapy. Licensed counselors, rehabilitation counselors, social workers, psychologists and psychiatrists are eligible for training as mental health specialists with NARHA or one of the associations that currently offer workshops and certification, including EAGALA (EAGALA, 2010).

\section{Overview of Current College and University Curricula}

After an internet-based search in 2010 for the current offerings in EAAT curricula at various colleges and universities in the United States, it appears that there is a growing trend to offering the EAAT courses to students. Using the keywords college and/or university combined with therapeutic riding, hippotherapy, equine facilitated psychotherapy, and equine facilitated learning, colleges and universities were identified that offered any type of EAAT curriculum. Thirty-one colleges and universities were identified as offering EAAT curricula including one master of arts program, six majors, three minors, four offering more 
than one course, thirteen offering a single course and two continuing education courses (Table 1). Three of the courses or certificate programs have been developed within the last year.

Another interesting trend is the use of horses in medical school curriculum electives. Currently, several medical schools in the United States have courses that have the medical students interact with horses as a means of understanding nonverbal communication. The purpose of these classes is to help facilitate doctor empathy toward patients. Stanford Medical School offers a class entitled, "Medicine and Horsemanship". The class is taught by Beverley Kane, MD, and is strictly a hands-on, groundwork-based program for first and second year medical students. Dr. Kane has written a textbook, "Medicine and Horsemanship" and provides a syllabus and presentation materials to other universities wishing to offer this class (Horsesensi, 2010). Comments by medical students who took a similar course at the University of Arizona Medical School were overwhelmingly positive (Buckley, 2002). One student noted that the class made him aware of how to observe a patient's attempts at communication, as well as the nonverbal cues he gives back in response to a patient's concerns.

NARHA surveyed colleges and universities offering EAAT-based course work and found that there was overwhelming interest in receiving support from NARHA in the form of educational materials and personnel for the process of therapeutic riding instructor certification (NARHA, 2009). A NARHA task force was formed in 2009 to develop a membership program for institutions of higher learning (NARHA, 2009). This higher education membership includes resource support for EAAT 
courses, as well as providing guidelines for criteria necessary for therapeutic riding instructor candidates to successfully complete EAAT training.

NARHA's interest in developing the educational aspects of the professions involved with EAAT is quite important. Although NARHA is not a regulatory agency, and currently certifies instructors through an internal process, there can be an assumption that the development of a higher education process could promote the licensure of certain professionals in EAAT. This would include the registered therapeutic riding instructors, which could bring increased marketability of their skills when searching for jobs in the profession. Licensure from a state board could also bring about possibilities for financial reimbursement from health insurance providers.

\section{How Can Curricula Be Implemented?}

For colleges and universities interested in developing courses based on equine assisted activities, the schools need to develop a center or forge a partnership with an existing NARHA center in their immediate vicinity. Several schools have developed a NARHA program in conjunction with their curriculum, although already having an equine science or equine studies department with facilities certainly gives schools a head start in developing a program.

Universities and colleges with agricultural science based programs currently have the preponderances of equine assisted activities and therapies courses, but there are four exceptions to the curricula being agriculture based. (1) There is a single class called "Equine Assisted Activity" in the Department of Occupational Therapy of Eastern Kentucky University in Richmond, Kentucky. (2) Stephens 
College, located in Missouri, has an innovative 3:2 program with Washington University in St. Louis, Missouri. Students complete three years of equine science studies at Stephens, then complete a two-year program at Washington University and graduate with a masters' degree in occupational therapy. (3) Asbury College in Wilmore, Kentucky offers an "Equine Facilitated Therapies" major in the school of Health, Physical Education and Recreation. (4) Bethany College in Bethany, West Virginia has just started a certificate program in equine facilitated therapy through their school of social work.

Some universities that have animal science programs have been slow to recognize the value of the horse in a different role than the traditional concept of a livestock animal. Horses did serve as an important part of a working farm in the past, but with the rise in the numbers of horses and ponies used for pleasure in today's world, their role has vastly changed (Tashjian, 1990). The legal status of a horse is that of a livestock animal, yet many equestrian studies, equine science and equine studies departments in the colleges and universities portray the horse as a companion animal. The "old-school" approach of the horse as livestock has kept some university or college-based programs from moving forward, but as the equine assisted activity profession grows, along with the job potential, many universities and colleges are starting to understand the student desire and need for equinebased courses. These schools have begun to attempt to meet the additional demand and desire by students for courses specifically in equine assisted activities and therapies. 
The type of student interested in this field varies tremendously. Students major in agriculture, special education, psychology, social work, exercise science, recreation therapy, physical therapy, occupational therapy or speech-language pathology. Many colleges and universities offer federally funded disability studies programs, where courses in equine assisted activities would be a natural fit for those interested in that aspect of their curriculum.

The backgrounds of students coming into a particular college or university can be quite diverse, so it is important to understand the variety of curriculum needs to produce a student who can become a serious professional in any of the equine assisted therapy fields.

The components necessary to become a well-rounded professional have their basis in several different university or collegiate departments or divisions. For those choosing to become a therapeutic riding instructor, a student would need to be wellversed in equine care and handling, riding skills, teaching methods, a good working knowledge of disabilities (including contradictions and precautions pertaining to riding horses by people with certain types of disabilities), and business or organizational skills. Students interested in equine facilitated mental activities need the same type of equine-related skills as well as disability expertise, but need to emphasize and develop skills from the fields of social work or psychology.

Colleges and universities that offer physical therapy, occupational therapy and speech-language pathology majors can offer classes and/or internships with the NARHA center they have affiliated with, and students can choose to gain additional horse management and riding skills through the college or university offerings or on 
their own. Equine assisted activities are gaining the attention of the students involved in these disciplines, and there are several programs that have at least one course available in equine therapy aimed at the medical professions.

\section{Universities and Research Potential for EAAT}

The field of EAAT has an overwhelming need for quality research to prove many of its positive effects on people with disabilities (MacKinnon, 2005). Many professionals that work in the various fields related to EAAT see the benefits of their work on a daily basis, but to become a legitimate "therapy" in the eyes of the medical establishment and insurance companies, more research needs to be conducted. The range of disabilities that are served by NARHA centers is extensive. Past research has focused on therapeutic riding and/or hippotherapy's benefits to children with cerebral palsy (Snider, Korner-Bitensky, Kammann, Warner, \& Saleh, 2007).

In 2002, a foundation was formed called Horses and Humans Research Foundation to address need for university based clinical research (Horses and Humans Research Foundation, 2009). The Horses and Humans Research Foundation was established to support research that will help the participants of EAAT programs, and to verify the importance of the horse and its influence on humans. This research is used to help explain and educate the medical establishment, parents, educators and donors on the positive effects of equine assisted activities and therapies. Guidelines for these grants of up to $\$ 100,000$ are usually reserved for universities and/or universities partnered with NARHA centers. The first university that received the grant in 2007, Washington University in St. Louis, Missouri, has 
just concluded and published their study "Changes in Dynamic Trunk/Head Stability and Functional Reach After Hippotherapy" (Shurtleff, Standeven, \& Engsberg, 2009). Lead researcher and occupational therapist Dr. Tim Shurtleff conducted the study over a period of 12 weeks to measure the motor control improvements of riders with cerebral palsy with the use of a motorized barrel and a video motion capture device. The study focused on children with spastic diplegia cerebral palsy, and showed that hippotherapy improved head and trunk stability, as well as upper extremity function (Horses and Humans Foundation, 2008). Not only did the subjects have immediate improvement in motor control of their trunk and head, but also the benefits of the hippotherapy were maintained in the children's lives after the completion of the riding program. Qualitative data were also drawn from surveys completed by the parents of the participants, which verified the clinical data.

Currently, two grants of $\$ 50,000$ each have been awarded to two universitybased programs from the Humans and Horses Foundation. The University of Quebec at Trois-Rivieries is studying hippotherapy and postural control in children with cerebral palsy, and the Good Hope Equestrian Training Center and the University of Miami have just completed a study funded by their grant on the effects of therapeutic riding lessons on social functioning in children with autism (Bass et al, 2009).

There have been a number of theses and dissertations that have been completed over the last twenty years on a variety of topics within the equine assisted activities and therapies field. These include topics ranging from measuring 
outcomes of riders with cerebral palsy to using parent/caretaker surveys to understand the psychological effects of being around horses on their children (Lentini \& Knox, 2008, Nimer \& Lundahl, 2007). In keeping with the current rise in the diagnosis of children with autism, many of these research reports are currently focusing on the effects of EAAT intervention on children with autism (Ospina et al, 2008).

\section{Service Learning Course Design Benefits}

The nature of equine assisted activities and therapies promotes the use of a hands-on approach, or the involvement of the student in the learning process (Wingfield \& Black, 2005). Wingfield and Black's study concluded that students believed that experiential learning helped them understanding the direction of their career choices. Maiga \& Westrom (2006) conducted a survey of students who were involved in a service learning project component of an Animal Systems Management course at the University of Minnesota. Students worked in teams to help solve farm management problems for local farmers. The majority of the students (95\%) felt the experience was positive and increased their leadership skills, as well as elevated their awareness of community problems and civic responsibilities.

The service learning benefits of equine assisted activities and therapies curriculum may be the most important aspect. Students who take these classes may not utilize their learning for a career, but volunteering for equine assisted activities and therapies programs can be a valuable part of service or experiential learning for the student, and lead them on a permanent path of being involved in community service throughout their lives. Equine assisted activities therapies depend heavily 
on the use of volunteers, and NARHA estimated that between 30,000 and 40,000 volunteers work at NARHA centers nationwide at least once a week (NARHA, 2009).

Several studies have focused on service learning for agricultural coursework in general, such as the study that examined experiential learning in animal sciences (Reiling, Marshall, Brendemuhl, McQuagge, \& Umphrey, 2003). This study focused on the students whose career goals were animal science, but very few (4\%) came from a farm background and therefore had little or no experience in working with farm animals. This University of Florida study looked at student learning based on the development of a practicum class to give the students hands-on experience. Researchers found that students taking the experiential courses felt strongly that the courses "stimulated their interest and facilitated their learning of animal science concepts".

Other studies have specifically looked at the involvement of students with either hippotherapy or therapeutic riding programs. Buswell and Leirou (2007) conducted a research project to determine perceived benefits of a service-learning experience for students volunteering with a NARHA therapeutic riding center. An interesting aspect of this study centered on the fact that most of the participants had not volunteered in any type of similar program. Students that were surveyed at the end of the course indicated that they greatly benefited from the experience by increasing their skills, personal gratification, self-esteem and confidence, as well feeling as though they really made a difference in the lives of people with disabilities. 
Another study examined service-learning and therapeutic horsemanship by using survey data from college students enrolled in Texas Tech University's Principles of Therapeutic Riding class (Brady, Lawver, Guay, Pyle, \& Cepica, 2005). Each student in the class was assigned to a participant in the Texas Tech University Therapeutic Riding Center program. The students worked in groups of three, and served as horse leaders and side walkers in a weekly therapeutic riding session. Students developed lesson plans and charted the progress of their participant, and eventually taught the plan to the rider by the end of the semester. The post-course survey conducted by the class instructor indicated students greatly increased their understanding of disabilities, from the viewpoint of the rider as well as their families. Comments on the survey also indicated high student desire to become therapeutic riding professionals or to continue community service either in this program or develop one in their own community.

No university or college can successfully offer courses in equine assisted activities and therapies without the benefit of a real on-going program with which students may become involved. All universities and colleges with majors or minors in therapeutic riding have NARHA centers on campus. The universities and colleges with one or two courses tend to affiliate or partner with existing NARHA programs that are already in their community and collaborate with facility administrators to teach or be involved with the curriculum.

\section{University Based Centers for Excellence in Developmental Disabilities}

Another advantage of being associated with a university system is being involved with a university that has a Center for Excellence in Developmental 
Disabilities. These centers are primarily concerned with education and training for those involved with the issues and needs that concern people with disabilities. One important aspect of this training is aimed toward university students, who, within any discipline, at any level of study, can become involved with the center through coursework or research. The university-based Centers for Excellence on Developmental Disabilities were originally created to serve those with intellectual disability through Public Law 88-164 in 1963. The centers are currently funded by the Administration on Developmental Disabilities in the U.S. Department of Health and Human Services, and serve a wide spectrum of disabilities. There are now 67 centers for Excellence on Developmental Disabilities that are partnered with research-based major universities, and are one-stop resources for services, education and research in the field of disabilities studies.

These universities, one in every U.S. state and territory, offer a blend of curriculum and resources for those seeking a better understanding of the disabilities' aspects of their curriculum. For example, West Virginia University's Center for Excellence in Disabilities has developed an interdisciplinary certificate program at the undergraduate and graduate levels and an undergraduate minor for those interested in completing a well-rounded curriculum in disabilities studies. Students may be involved in health care (physical therapy, occupational therapy, speech language pathology) or students enrolled in psychology or social science majors (West Virginia University Center for Excellence in Disabilities, 2009).

This certificate or minor produces a knowledgeable individual on every aspect of disabilities, including requirements for accumulating volunteer hours in 
working with people with disabilities. Universities that partner with or are affiliated with equine assisted activity and therapies centers provide the perfect venue for such volunteer hours, and provide part of missing hands-on education that should be required for students considering becoming an EAAT professional.

\section{Development of On-Line Curricula}

What are the options if an equine assisted activity and therapy center is not nearby the university or college? Colleges and universities have been dragged (some kicking and screaming) into the age of technology with the use of online classes (Benton, 2009). A recent study from the Department of Education confirms that online courses can be as effective as traditional face-to-face courses in achieving measurable outcomes (U. S. Department Of Education, 2009). For many students, including students already working or with transportation issues, taking classes online is perfect way to receive a degree from an accredited college or university, while receiving what could be the same quality of education that students receive in the classroom. EAAT curricula, while containing hands-on components, could easily adapt themselves to students who do have access to a NARHA center, which may not be near the college or university, but could provide the missing hands-on component. Working or volunteering day-to-day in a NARHA center cannot not be replicated in any manner by an online class, but the essential ingredients of being a professional in EAAT could be learned through properly structured online classroom work. The beauty of NARHA is that all member centers have to follow the same standards and guidelines, so a student completing an online degree using the hands-on component from a NARHA center would receive the same background as a 
student who resided on a campus that partnered or affiliated with a NARHA center nearby.

Advances in multimedia use, such as videos, PowerPoint presentations and voice lectures are found in current online classrooms. Incorporating a visual curriculum into the online classroom becomes easier every day, and could be an important reason why the EAAT on-line curriculum could easily be adapted. Students who are in the teaching and modeling phase of their curriculum could also videotape themselves and send those video clips to their online instructors. The possibilities are endless, and more avenues of convenience and ease with the use of technology appear on a daily basis.

The online concept could be very advantageous to the adult or mature learner, who finds it difficult to attend college classes in the traditional on-campus way, but could manage to do the classroom work online. These types of students could seek out a NARHA facility close by to volunteer and complete the hands-on component.

One university program at West Virginia University has a continuing and professional education hybrid course (online and hands-on components) called Introduction to Equine Assisted Activities and Therapies (West Virginia University Extended Learning, 2010). This course does not count as academic credit, but instead provides continuing education units that are required for physical therapists, occupational therapists and speech language pathologists to maintain their licenses for practice. The course is also aimed at individuals interested in understanding the field of equine assisted activities or therapies, including high 
school or college students, practitioners and/or consultants in the therapy fields, or parents and volunteers involved with equine assisted activity and therapies programs.

St. Andrews Presbyterian College in North Carolina recently added online course work for a program in their Center for Adult and Professional Education program called Therapeutic Horsemanship Business Management. Degree-seeking individuals for college credit can take these classes (St. Andrews Presbyterian College, 2010).

\section{The Educational Process Needed for a Professional Track into Equine Assisted}

\section{Activities}

A task force was developed by NARHA in 2009 to develop a higher education membership for colleges and universities that wish to develop curriculum for EAAT classes. This membership offers three levels of participation, including institutions that are exploring the possibilities of developing curriculum, those that have curriculum, but currently do not offer certification of riding instructors, and those who have curriculum and wish to offer certification of riding instructors. The task force also developed a memorandum of understanding to establish a partnership with a college or university and a NARHA center, as well as a list of suggested courses that should be considered in a well-rounded curricula for equine assisted activities and therapies professionals. This higher education task force is establishing a baseline of guidelines to develop NARHA instructors with academic backgrounds and should begin to be implemented as a program in 2010 (NARHA, 2010). 


\section{What Currently is Being Offered?}

There is a general acknowledgement in the horse-related business world that many students interested in pursuing a career in the horse industry lack a solid background in business. Knowledgeable business people who happen to also be equine specialists often administer well-run and successful NARHA facilities. Unfortunately, graduates that have successful and experienced backgrounds in equine activities often believe their talent is enough for them to be successful in the industry. Colleges and universities that recognize the importance of a business background are incorporating those classes into the equine majors or minors they offer. Schools that incorporate agricultural business which includes accounting, entrepreneurship and management as part of the curricula produce students that enter the horse industry understanding what is expected of them, from managing their own finances to directly managing or developing a business of their own. Equine assisted activity and therapies centers are normally non-profit businesses, so the curriculum must include skills and knowledge about developing a non-profit business, which includes applying for a 501(3) c, managing a board of directors, and understanding and managing a variety of types of employees and volunteers.

Administrators at colleges and universities are in the forefront of the battle for students and their recruitment. Keeping ahead of what majors and minors have market value is an important asset for an administrator to have. EAAT is an attractive field for those students interested in a career with horses, as it is growing in numbers of centers with associated jobs. Students already in the health related professions programs at colleges and universities could be exposed to EAAT by one 
or two classes as part of their elective coursework. Centers can also develop internships for these students, as hands-on internships are normally required in all of the health-related professions.

\section{Terminology}

As it can be observed from these varied offerings, the terminology involved with the naming of courses and sequences is varied. This is another factor in the need for some oversight and guidance from NARHA. Terminology in the various fields of equine assisted activities has been confusing in the past. There has been a strong effort by both NARHA, its affiliate partner The American Hippotherapy Association, and the Horses and Humans Foundation to clarify the terminology used by the professionals in the fields. The terms hippotherapy and therapeutic riding are often used interchangeably, but as explained earlier in this article, have two very distinct meanings and requirements of professionals involved. The distinction in terminology is important in terms of research needs for either field, and college and university training can go a long way into helping make students and, therefore, the public, understand the differences.

\section{Survey Results}

An email survey was sent in 2009 to all 225 Premier Accredited NARHA Centers' contact administrators with working email addresses (Table 2). These Premier Accredited NARHA Centers were identified through the database listing of all center members on NARHA's website. These are centers that have been reviewed by trained NARHA evaluators as to adherence to mandatory and regular standards, and are inspected every five years (NARHA, 2009). Not all NARHA centers choose to 
reach this level of accreditation, and there are an additional 500 plus centers that are either working toward this level of accreditation or have chosen not to pursue this type of membership.

Premier Accredited NARHA Center administrators were asked two questions:

1. Is your center a partner with or affiliated with a college or university, and if so, which one? What do you perceive as the advantages or disadvantages of having a relationship with the college or university?

2. To your knowledge, does that college or university offer any equine assisted activity or therapy courses (such as therapeutic riding, hippotherapy, etc.) in their curriculum?

Approximately 12\% (27) of the surveys were returned. Almost half of the centers that responded (44\%) (13) affirmed that they were affiliated or partnered with a college or university in some type of manner and $11 \%$ (3) of the respondents said that the university or college they partnered with offered either a major, NARHA instructor training or course work in equine assisted activities and therapies.

The responses (Table 3) fell into six categories (with corresponding number of responses):

1) NARHA programs that are part of a university program (5).

2) Two NARHA programs that partner with a university or college (but are independent non-profit entities) (2).

3) NARHA programs that provide internships for universities or colleges (3).

4) NARHA programs that utilize volunteers from universities or colleges (5) 
5) NARHA programs that use university or college facilities, but the university or college have no curriculum or partnership (1).

6) NARHA programs that partner with universities or colleges for research purposes only (1).

\section{NARHA programs that are part of a university program}

NARHA programs that are an integral part of a university or college are those with which the university or college has a financial relationship. Two of the respondents to the survey, St. Andrews Presbyterian College of Laurinburg, North Carolina and Centenary College of Hackettstown, New Jersey have well-established programs that offer full training toward NARHA registered instructor status. St. Andrews offers a four-year degree Bachelor of Arts degree in therapeutic riding, and runs a NARHA premier accredited program called Ride Like A Knight.

Centenary College's program offers full NARHA instructor training, but is not a degree program. Their facility is called Therapeutic Riding at Centenary (TRAC), and is part of the college equestrian program. Tarleton University in Stephenville, Texas operates a NARHA program (TREAT) as a laboratory for one undergraduate class, Equine Assisted Therapy. The College of Veterinary Medicine at Washington State University in Pullman offers a NARHA program called People-Pet Partnership (PATH). They do not offer classes in equine assisted activities or therapies, but give veterinary students and undergraduates practicum credit for volunteering. 


\section{NARHA programs that partner with a university or college (but are independent non-profit entities)}

Pikes Peak Therapeutic Riding Center of Pikes Peak, Colorado has a relationship with Pikes Peak Community College (although not formal) that involves center instructors participating in curriculum as guest lecturers. In a reverse positive financial relationship for the college, volunteers from Pikes Peak Therapeutic Riding Center also take courses at the college in Equine Studies. Saddle Up! of Nashville, Tennessee partners with Middle Tennessee State University for internships, guest lecturers and volunteers. Middle Tennessee State also offers a class on therapeutic riding within their equine studies curriculum.

\section{NARHA programs that utilize volunteers from universities or colleges.}

Charleston Area Therapeutic Riding in Johns Island, South Carolina has a relationship with the Medical University of South Carolina. Physical therapy and occupational therapy students volunteer at the center for some of their learning

hours. Charleston Area Therapeutic Riding is also planning to offer volunteer hours to speech-language pathology students. Riverwood Therapeutic Riding Center of Tobaccoville, North Carolina receives volunteers from Wake Forest University APO service fraternity. Buffalo Therapeutic Riding Center of Buffalo, New York is surrounded by several small colleges, all of which send volunteers through a local outreach program.

\section{NARHA programs that provide internships for universities or colleges}

Windrush Farm Therapeutic Equitation, Inc. in Boxford, Massachusetts provides internships for two nearby colleges, Endicott College and Gordon College. 
These students generally major in education, art and recreational therapies and psychology. The director of Windrush, Josselyn Shaughnessy, felt this relationship benefited their staff by enhancing the energy and opportunities that their program could offer their students. Little Bit Therapeutic Riding Center in Woodinville, Washington has internships available with three schools: Columbia University, University of Washington and Loma Linda University.

5. NARHA programs that use university or college facilities, but the university or college has no curriculum or partnership.

We Can Ride, Inc. of Minnetonka, Minnesota uses the University of Minnesota's Equine Center at the veterinary school. The school allows We Can Ride to use the arena, but the program pays for parking and stalls.

\section{NARHA programs that partner with universities or colleges for research purposes only.}

Therapeutic \& Recreational Riding Center of Glenwood, Maryland recently helped Stevenson University complete a research project on therapeutic riding. This center is also currently involved in a research project with the University of Mississippi.

Several survey respondents indicated although they were not partnered or affiliated with a college or university, they felt it would a tremendous asset to their program if they could, citing volunteer pools as well as research opportunities. One of the more interesting responses, however, was from a NARHA Premier Center that was affiliated with a large state university. The administrator felt that the advantages of the affiliation included plentiful supplies of volunteers, and assess to 
university resources, such as veterinarians and office equipment. The disadvantages seemed to be related to restrictions on fund-raising abilities and concerns about liability from university officials.

This survey provides an excellent window into the types of partnerships that colleges and universities have with NARHA centers. The addition of the guidelines and standards for curriculum development set forth by NARHA in the newly proposed Institutional Membership will certainly help strengthen the abilities of universities and colleges to understand what type of curriculum will best serve the students who wish to enter the fast growing field of equine assisted activities and therapies.

\section{Conclusions}

The need for EAAT curricula in university and college curriculums is clear. There is a growth in schools offering basic curricula for this field, which corresponds with the growth of NARHA centers and the interest from students enrolled in universities or colleges. For example, D’Youville College just received a $\$ 31,000$ grant from the Community Foundation for Greater Buffalo to start up a hippotherapy treatment program (D’Youville College, 2009).

Many colleges and universities are redesigning their general curriculum to better serve the students and target specific skills needed for the job market. They must understand the demand for such a curriculum and specify the goals and needs of the curriculum (Phillips, Settoon, \& Phillips, 2008). The field of equine assisted activities and therapies requires specific skills, and colleges and universities must examine their ability to provide the variety of course selections to adequately fill 
those needs. Even if a student is not involved in an EAAT major or minor, one study determined that student involvement in a hands on any singular equine based courses may improve and strengthen life skills, such as leadership, attitudes and values (Evans, Jogan, Jack, Scott, \& Cavinder, 2009).

There is potential for difficulty in presenting equine assisted activities and therapies curricula to students. The partnership between the NARHA center and the university must be mutually respectful and professional on all levels. Unless the NARHA center is owned and operated by the university or college, the quality and quantity of services provided by the NARHA center are only as good as the personnel involved at the center. Instructors for the university or college classes must be NARHA certified instructors. This may severely limit the abilities of the college or university to locate an individual within the NARHA partner center that has the academic background and/or is willing to become part of the faculty. As the field of EAAT academic needs develop along with the curriculum, there will be growing pains to match adequate college level instruction with the type of curriculum that needs implemented to be successful.

Many colleges and universities have the type of course work available that would help produce a well-rounded EAAT professional. College based courses would help the deficit of disability knowledge that is commonly acknowledged to be lacking in current NARHA certification materials. Although EAAT professionals get lots of hands-on experience while working or training with an EAAT facility, they also must do "off-hours" research to get pertinent information about the disabilities they encounter. 
A candidate for employment and leadership in the field of equine activities and therapies needs to have a variety of skills in horsemanship, teaching, disabilities and/or special education, business, psychology, health sciences and communications. The ideal curricula would have its base in the equine science or equine management departments, so a student could receive adequate training in both riding, riding teaching methods, equine care, training and handling. The student should be required to take a variety of business classes, including management (especially for non-profits), finances, entrepreneurship, and management of individuals and teams. Communication studies departments can be a source of courses such as business and professional communication and public speaking. Course work in disabilities studies and special education is important, as well as classes based in the health fields, such as anatomy, kinesiology or exercise sciences. Psychology departments offer basic courses in learning, cognition and counseling. Manual communication or communication disorders classes (usually part of a speech/ language pathology program) should be considered for part of the curricula. A listing of departments and specific courses for EAAT curricula based on a multidisciplinary approach, developed by the author of this paper, is included in Appendix B.

College students and equine assisted activities centers are a match made in heaven. NARHA centers can provide the type of service learning and volunteering potential unlikely found in most other academic curriculum. Students can provide NARHA centers an important personnel aspect of their operations, volunteers, while infusing the enthusiasm of youth into their programs. The student interested in a 
job as an EAAT professional has a growing list of universities and colleges that can offer the full spectrum of training for their career choice. The challenge is for universities and colleges to develop and promote their EAAT curriculum in a manner that is carefully planned out and deliberate. There may be a rush to provide these popular types of courses, but unless all elements are in place to truly provide a well-rounded program, the administrative support will not remain. The field of EAAT is poised to make real strides professionally with the implementation of the new NARHA institutional membership with colleges and universities. Colleges and universities wishing to become part of the fast growing field of EAAT need to decide what level of coursework they wish to offer students, and either develop a relationship with a nearby NARHA center or seriously consider starting a NARHA program of their own. 
Table 1.

Universities and Colleges in the United States that Offer Equine Assisted Activities and Therapies Curricula

\begin{tabular}{|c|c|}
\hline College/University & Department/Course \\
\hline \multirow[t]{2}{*}{ Asbury College } & Health, Physical Education and Recreation \\
\hline & Equine Facilitated Therapies Major \\
\hline \multirow[t]{2}{*}{ Bethany College } & Social Work \\
\hline & Equine Facilitated Therapy Certificate Program \\
\hline \multirow[t]{3}{*}{ California State at Fresno } & Global and Professional Education \\
\hline & Introduction to Equine Assisted Activities and \\
\hline & Therapies \\
\hline \multirow[t]{2}{*}{ Cazenovia College } & Equine Studies \\
\hline & Course: Therapeutic Riding Instruction \\
\hline \multirow[t]{2}{*}{ Centenary College } & Equine Studies \\
\hline & Approved NARHA Instruction Training Course \\
\hline \multirow[t]{2}{*}{ College of Central Florida } & Equine Studies (Associate Degree) \\
\hline & Therapeutic Riding Management Specialization \\
\hline \multirow[t]{2}{*}{ Colorado State University } & Equine Sciences \\
\hline & Practicum in Therapeutic Riding \\
\hline \multirow[t]{2}{*}{ Judson College } & Equine Science \\
\hline & Animal Partnership \\
\hline \multirow[t]{2}{*}{ Lake Erie College } & Equine Studies \\
\hline & Therapeutic Horsemanship Concentration \\
\hline
\end{tabular}


Middle Tennessee State University Horse Science

Equine Assisted Therapy

North Dakota State University Equine Studies

Therapeutic Horsemanship Minor

Ohio University Southern Equine Studies (Associate Degree)

Certificate in Therapeutic Riding

Therapeutic Riding

Administrative Aspects of TR

Equine Assisted Intervention Methods

Pennsylvania State University Animal Science

Equine Facilitated Therapy

Prescott College Master of Arts Program

Counseling and Psychology/Education

Equine-assisted Mental Health

Equine-assisted Learning

Rocky Mountain College Equestrian Studies

Major: Therapeutic Riding Instruction

St. Andrews Presbyterian College Major: Therapeutic Riding

St. Mary's of the Woods College Equine Studies

Principles of Therapeutic Riding 
Santa Rosa Junior College

Slippery Rock University

Stanford University

Stephens College

SUNY Cobleskill

Tarleton State University

Texas Tech University
Three classes: Introduction to Therapeutic

Riding Principles; Therapeutic Riding Program

Procedures; Therapeutic Riding Program

Operations

Exercise and Rehabilitative Sciences

Equine Facilitated Riding (required for Adapted

Physical Education Minor program)

School of Medicine

Medicine and Horsemanship

Equestrian Science

3:2 Program with Washington University

B.A. from Stephens/Equestrian Science

Master's in Occupations Therapy:Washington

University

Animal Science

Occupational Experience Riding Instruction

Equine Science

Equine Assisted Therapy

Animal Science

Introduction to Hippotherapy

Advanced Therapeutic Riding

Equine Assisted Mental Health 


\begin{tabular}{|c|c|}
\hline University of Connecticut & Animal Science \\
\hline & Equine Science: Therapeutic Riding Minor \\
\hline University of Findlay & Introduction to Therapeutic Riding \\
\hline University of Indiana & Health, Physical Education \& Recreation \\
\hline & Introduction to Equine Assisted Activities \\
\hline University of New Hampshire & Equine Studies \\
\hline & Specialization (major) Therapeutic Riding \\
\hline West Virginia University & Davis College of Agriculture, Natural Resources \\
\hline & and Design \\
\hline & Equine Assisted Activities \& Therapies I \& II \\
\hline & (WVU Online) Professional and Continuing \\
\hline & Education \\
\hline & Introduction to Equine Assisted Activities \& \\
\hline & Therapies \\
\hline William Woods University & Equestrian Studies \\
\hline & Survey of Therapeutic Riding \\
\hline Wilson College & Equine Facilitated Therapeutics Major \\
\hline Virginia Intermont College & Equine Studies \\
\hline & Therapeutic Riding \\
\hline
\end{tabular}


Table 2. Premier Accredited NARHA Center survey

1. Is your center a partner with or affiliated with a college or university, and if so, which one? What do you perceive as the advantages or disadvantages of having a relationship with the college or university?

2. To your knowledge, does that college or university offer any equine assisted activity or therapy courses (such as therapeutic riding, hippotherapy, etc.) in their curriculum? 
Table 3. University or college and NARHA relationships based on survey results

\begin{tabular}{|c|c|c|}
\hline Name of College/University & NARHA program & Nature of relationship \\
\hline Centenary College & TRAC & $\begin{array}{l}\text { Owns center, offers } \\
\text { instructor training }\end{array}$ \\
\hline St. Andrews Presbyterian College & Ride Like A Knight & $\begin{array}{l}\text { Owns center, offers } \\
\text { major in EAAT }\end{array}$ \\
\hline Tarleton University & TREAT & $\begin{array}{l}\text { Owns center, offers } \\
\text { one class }\end{array}$ \\
\hline Washington State University & PATH & $\begin{array}{l}\text { Owns center, no } \\
\text { classes }\end{array}$ \\
\hline Middle Tennessee State University & Saddle Up! & $\begin{array}{l}\text { Partnership, center } \\
\text { provides guest } \\
\text { lecturers, volunteers }\end{array}$ \\
\hline Pikes Peak Community College & Pikes Peak TRC & $\begin{array}{l}\text { Partnership, center } \\
\text { provides lecturers }\end{array}$ \\
\hline $\begin{array}{l}\text { Medical University of South } \\
\text { Carolina }\end{array}$ & Charleston Area TR & $\begin{array}{l}\text { PT, OT students } \\
\text { volunteer }\end{array}$ \\
\hline Wake Forest University & Riverwood TRC & Volunteers \\
\hline $\begin{array}{l}\text { Endicott College, } \\
\text { Gordon College }\end{array}$ & Windrush Farm & Internships \\
\hline $\begin{array}{l}\text { Columbia University, } \\
\text { University of Washington, } \\
\text { Loma Linda University }\end{array}$ & Little Bit TRC & Internships \\
\hline University of Minnesota & We Can Ride! & Center rents facilities \\
\hline Stevenson University & $\begin{array}{l}\text { Therapeutic \& } \\
\text { Recreational Riding } \\
\text { Center }\end{array}$ & Partner for research \\
\hline
\end{tabular}




\section{References}

All, A. C., \& Loving, G. L. (1999). Animals, Horseback Riding, and Implications for Rehabilitation Therapy. Journal of Rehabilitation, 65(3), 49-57.

American Hippotherapy Association (2009). Retrieved September 14, 2009, from http://www. americanhippotherapyassociation.org/

Bass, M. M., Duchowny, C. A., \& Liabre, M. M. (2009). The effect of therapeutic horseback riding on social functioning in children with autism. Journal of Autism Developmental Disorders, 39(9), 1261-1267.

Benda, W., McGibbon, N. H., \& Grant, K. L. (2003). Improvements in muscle symmetry in children with cerebral palsy after equine-assisted therapy (hippotherapy). The Journal of Alternative and Complementary Medicine, 9(6), 817-825.

Bender, M., \& McKenzie, S. (2007). Therapeutic Driving. Palaestra, 23, 45-46.

Benton, T. (2009). Online learning: reaching out to the skeptics. The Chronicle of Higher Education. Retrieved March 18, 2010 from http://chronicle.com/article/Online-Learning-ReachingOut/48375/?sid=at\&utm_source=at

Bizub, A. L., Joy, A., \& Davidson, L. (2003). "It's like being in another world": Demonstrating the benefits of therapeutic horseback riding for individuals with psychiatric disability. Psychiatric Rehabilitation Journal, 26(4), 377-385.

Brady, H. A., Lawver, D. E., Guay, K. A., Pyle, A. A, \& Cepica, N. T. (2005). Principles of therapeutic riding as a service-learning course within an agricultural curriculum. NACTA, 49(4), 19-23. 
Buckley, M. (2002). What medical students learn from horses. Alternative \& Complementary Therapies, 8(2), 102-109.

Buswell, D., \& Leriou, F. (2007). Perceived benefits of students' service-learning experiences with hippotherapy. Palaestra, 23(1), 20-25.

Center For Excellence In Disabilities (2009). Retrieved September 25, 2009, from http://www.cedwvu.org/

Chandler, C. (2003). Sensory integration and therapeutic riding at summer camp: Occupational performance outcomes. Physical \& Occupational Therapy in Pediatrics, 23(3), 51-64.

D'youville Alumni News (2009, June). Grant to help start hippotherapy program. Retrieved February 5, 2010, from http://alumni.dyouville.edu/news/27843/GRANT-TO-HELP-STARTHIPPOTHERAPY-PROGRAM.htm

EFMHA (2009). What is EFMHA? Retrieved September 26, 2009, from http://www.narha.org/SecEFMHA/WhatIsEFMHA.asp

EAGALA (2010). Retrieved September 29, 2010, from http://www.eagala.org/

Evans, P. A., Jogan, K. S., Jack, N. E., Scott, A., \& Cavinder, C. A. (2009). University students may be better prepared for life after working with horses. Journal of Equine Veterinary Science, 29(5), 451-452.

Fletcher, C. (2008, December). Real horsepower: changing the lives of children with autism. Retrieved November 17, 2009, from Texas NonProfits http://www.txnp.org/articles/articles.asp?ArticleID=9446 
Fleck, C. A. (1997). Hippotherapy: Mechanics of human walking and horseback riding. In B. Engel (Ed.), Rehabilitation with the Aid of the Horse: A Collection of Studies (pp.153-176). Durango, CO: Barbara Engel Therapy Services.

Horses And Humans Research Foundation (2009). Awarded Projects. Retrieved November 17, 2009, from http://www.horsesandhumans.org/Research_AwardedProjects.html

Horsesensi (2010). Retrieved March 20, 2010, from http://www.horsensei.com/ Hubbard, S. L. (2007). A chronological and historical review of research related to hippotherapy. In B. Engel \& J. McKinnon (Eds.), Enchancing human occupation through hippotherapy (1st ed., pp. 46-69). Bethesda: American Occupational Therapy Association.

Lentini, J. A., \& Knox, M. S. (2008). A Qualitative and Quantitative Review of Equine Facilitated Psychotherapy (EFP) With Children and Adolescents. The International Journal of Pyschosocial Rehabilitation, 13(1), 17-30.

MacKinnon, J. R. (2007). What is the state of hippotherapy research, and where should we go from here? In B. Engel \& J. Mackinnon (Eds.), Enchancing human occupation through hippotherapy (1st ed., pp. 158-173). Bethesda: American Occupational Therapy Associations, Inc..

Maiga, H. A., \& Westrom, L. E. (2006). Integration of service learning in animal science curriculum. NACTA, 50(3), 57-64.

McGibbon, N. H., Benda, W., Duncan, B. R., \& Silkwood-Sherer, D. (2009). Immediate and long-term effects of hippotherapy on symmetry of adductor muscle activity and functional ability in children with spastic cerebral palsy. Physical Medicine and Rehabilitation, 90(6), 966-974. 
NARHA (2009). Who is NARHA? Retrieved March 12, 2010, from http://www.narha.org/WhoIsNARHA/About.asp

NARHA (2010). Retrieved August 29, 2010, from http://www.narha.org/

Nimer, J. \& Lundahl, B. (2007). "Animal-assisted therapy: a meta-analysis". Anthrozoos 20(3), 225-38.

Ospina, M. B., Seida J. K., Clark, B., Karkhaneh, M., Hartling, L., Tjosvold, L., et al. (2008). Systematic reviews of psychosocial interventions for autism: an umbrella review. Developmental Medicine \& Child Neurology, 51(2), 95-104.

Pauw, J. (2000). Therapeutic horseback riding studies:problems experienced by researchers. Physiotherapy, 86(10), 523-527.

Phillips, A. S., Settoon, R. P., \& Phillips, C. R. (2008). Enhancing a curriculum: a focus on the development process. College Student Journal, 42(4), 1070-1074.

Reiling, B. A., Marshall, T. T., Brendemuhl, J. H., Mcquagge, J. A., \& Umphrey, J. E. (2003). Experiential learning in the animal sciences: development of a multispecies large-animal management and production practicum. Journal of Animal Science, 81(12), 3202-3210.

St. Andrews Presbyterian College (2010). Center for Adult and Professional Studies. Retrieved November 26, 2010 from http://www.sapc.edu/Admissions/sandhills/thbusmngmt.php

Shurtleff, T. L., Standeven, J. W., \& Engsberg, J. R. (2009). Changes in dynamic trunk/head stability and functional reach after hippotherapy. Physical Medicine and Rehabilitation, 90(7), 1185-1195. 
Snider, L., Korner-Bitensky, N., Kammann, C., Warner, S., Saleh, M. (2007). Horseback riding as therapy for children with cerebral palsy: is there evidence of its effectiveness? Physical \& Occupational Therapy Pediatrics. 27(2), 5-23.

Tashjian, R. (1990). Expanding the concept of the companion animal. Equine Veterinary Science, 10(3), 160-161.

Taylor, R. R., Kielhofner, G., Smith, C., Butler, S., Cahill, S. M., Ciukaj, M. D., et al. (2009). Volitional change in children with autism: a single-case design study of the impact of hippotherapy on motivation. Occupational Therapy in Mental Health, 25(2), 192-200.

Thurm, A., Lord, C., Lee, L., \& Newschaffer, C. (2007). Predictors of language acquisition in preschool children with autism spectrum disorder. Journal of Autism and Developmental Disorders, 37(9), 1721-1734.

U. S. Department Of Education (2009). Evidence-based practices in online learning: a meta-analyis and review of online learning. Retrieved April 14, 2010, from http://www2.ed.gov/rschstat/eval/tech/evidence-basedpractices/finalreport.pdf

West Virginia University Center for Excellence in Disabilities (2009). Retrieved May 2, 2010 from http://www.cedwvu.org/

West Virginia University Extended Learning (2010). Retrieved September 22, 2010 from http://elearn.wvu.edu/Continuing/

Whitaker, P. (2007). Provision for youngsters with autistic spectrum disorders in mainstream schools: what parents say - and what parents want. British Journal of Special Education, 34(31), 170-178. 
Wingfield, S. S., \& Black, G. S. (2005). Active versus passive course designs: the impact on student outcomes. Journal of Education for Business, 81(2), 119123.

Yorke, J., Adams, C., \& Coady, N. (2008). Therapeutic value of equine-human bonding in recovery from trauma. Anthrozoos, 21(1), 17-30. 
CHAPTER 3: ESSAY 3

\title{
Measurement of Outcomes for NARHA Therapeutic Riding Instructors and Centers
}

\author{
Carol C. Petitto \\ West Virginia University \\ College of Agriculture, Natural Resources and Design
}




\section{Measurement of Outcomes for NARHA Therapeutic Riding Instructors}

\section{And Centers}

There has been a general acknowledgement among those involved with North American Riding for the Handicapped (NARHA) therapeutic riding programs that combining horses and people with disabilities has been an overwhelmingly positive endeavor. Parents and caretakers, the instructors and volunteers all witness firsthand what improvements cognitively, physically and psychosocially occur on a daily basis with participants in NARHA based programs. During the 40 years of NARHA's existence, guidelines and standards for member centers to follow have evolved, all based on best practices and practical use in the field (NARHA, 2009). Most NARHA center administrators and instructors understand the benefits of measuring outcomes of participants in programs, but developing a procedure or procedures that would produce evidence of therapeutic riding's benefits has been largely languishing in the frustration of how to document the results from the wide variety of disabilities that NARHA centers serve. Many NARHA centers have developed their own methods of measuring outcomes for their own internal needs, including documenting rider progress for instruction purposes, as well as being able to disclose the positive results of center activities to funding sources.

It is the intention of this article to assess how riders with disabilities in therapeutic riding programs are currently being evaluated as to the progress of their improvement, from the viewpoint of the NARHA therapeutic riding instructors, parents and caretakers involved with these riders and their daily activities. From this overview, a more consistent and standardized form of reviewing the progress of 
therapeutic riding students can be established by NARHA centers and, therefore, making it much easier to identify and establish the benefits of therapeutic riding from a data-based methodology.

\section{What is Therapeutic Riding?}

Therapeutic riding is the profession of teaching riding skills to individuals with disabilities. As part of the umbrella terminology of equine assisted activities, therapeutic riding specifically targets riding activities that include the development of adaptive or traditional riding skills that are taught by a NARHA registered instructor. NARHA has developed a method of certification for therapeutic riding instructors, and has also developed certification standards for those interested in using psychotherapy, as well as for those instructors wishing to incorporate vaulting or driving in their lessons. (NARHA, 2009). Therapeutic riding has physical, educational, social and psychological benefits (All \& Loving, 1999).

Centers that conduct therapeutic riding lessons under the guidance of NARHA instructors all follow a similar format. There are specific components to the lesson structure, and NARHA instructors are trained to write lesson plans that include goals and objectives, as well as clearly defined segments of the lesson itself, including warm-up exercises, review of previous skills learned, new skills introduced, a game or activity, and a cool-down (Bass, Duchowny, \& Liabre, 2009). Mounting and dismounting of the horse is very controlled, and mounting often involves the use of special ramps so those riders in wheelchairs or walkers can easily assess the horse's back. 
Volunteers play an important role in all NARHA centers, as many riders require three volunteers per session. Often the rider with a disability will require assistance from both sides of the horse, as well as a horse handler. The side aide volunteers follow the direction of the NARHA instructor, and may need to lend support to the rider with a variety of hand or foot holds. Many beginning therapeutic riders use all available volunteer help, and progress to the eventual goal of independent riding.

NARHA centers are an important part of the community in which they are based. They extensively utilize volunteers from the population base, and often employ a number of professionals either full-time or part-time with their facility.

Therapeutic riding has developed into a professional field of work and study through the founding of NARHA in 1969, which provides standards for safety and procedures for participating therapeutic riding centers. With the number of centers growing both nationally and internationally, NARHA continually strengthens and updates those standards, and through the implementation of new programs tries to meet the needs of those with disabilities on every level. NARHA has developed a higher education membership for colleges and universities to partner with NARHA centers to help facilitate academic development of equine assisted activities and therapies students. This partnership could potentially lead to higher standards on a professional level for NARHA therapeutic riding instructors, as well as introducing research possibilities for the universities or colleges involved.

Another field that often is confused with or compared to the field of therapeutic riding is hippotherapy. Hippotherapy is a form of therapy using the 
horse as the therapy tool and, therefore, involves physical therapists, occupational therapists and speech-language pathologists as the professionals using the horse to provide therapy to their clients (AHA, 2009). For the purposes of this article we are only reviewing therapeutic riding measurement outcomes and, therefore, will not review research articles that address hippotherapy. Confusion does enter, however, as some articles use the term hippotherapy, but are actually referring to therapeutic riding, and vice versa (Silkwood-Sherer \& Warmbier, 2007). Professionals related to both of these fields have a consensus that participants of hippotherapy and therapeutic riding receive similar benefits (Debuse, Chandler \& Gibb, 2005). These professionals have outcome measurement tools available as part of their professions, and research studies involving hippotherapy have usually involved a measurement tool of the therapist's choice in their evaluation of patient progress. Many NARHA therapeutic riding centers incorporate hippotherapy as one of the services they offer, but when hippotherapy clients improve to the level of being able to learn riding skills, they often graduate into therapeutic riding programs.

Many NARHA centers and therapeutic riding instructors incorporate equine facilitated psychotherapy (EFP) and equine facilitated learning (EFL) based activities in their programming. Both EFP and EFL bring horses, mental health specialists, equine specialists and clients together to promote "human growth and development by bringing people and equines together in mutually beneficial ways." (EFMHA, 2009). This particular specialty is in its infancy, so current research and data supporting its validity and use is quite scarce. 


\section{Review of Literature}

There has been very little published research examining measurable outcomes for therapeutic riding. Many of the measurement outcomes involved in published studies focus on the use of evaluation instruments that involve diagnostic tests and clinically based evaluations, which involve the use of trained personnel. The field of equine assisted activities and therapies suffers from a lack of research and, therefore, the proof that the insurance companies demand to reimburse their policyholders for their treatments. This is true even for hippotherapy, which has the involvement of professionals trained in specific medically based fields.

It can be surmised that a profession that has slowly developed its standards and numbers of active centers, while battling the reality of the economics of running non-profit entities, would be reluctant to pursuing any added tasks. However, many successful NARHA centers have discovered the importance of verifying their positive results involving their participants for their financial backers through the use of yearly reports.

Miller and Alston (2004) researched the measurement outcome issue through parent interviews. The purpose of the research was to understand parents' perceptions of the benefits of therapeutic riding, not to add to any methodology to measure outcomes. This research was important in adding to our understanding that parents and/or caretaker's observations of their children needs to be a consideration for measurement outcome data. Miller and Alston developed a questionnaire after a thorough review of literature related to therapeutic riding. Five sets of parents were asked about their child's involvement in a therapeutic 
riding program, as well as their opinions on therapeutic riding being a part of school curriculum for special education classes. The key question in the Miller and Alston study related to measurement outcomes was "As a result of the therapeutic riding program, have you noticed any change in the child's performance in school and at home?" The parents reported that they believed many improvements occurred both socially and academically for their child because of the therapeutic riding program.

An Australian based study (Davis et al, 2008) focused on measuring outcomes of therapeutic riding on the physical function and quality of life of children with cerebral palsy. The Davis et al (2008) study included subjective outcome measures for parents' assessments, the KIDSCREEN, a socially sensitive measurement instrument that scores children from ages 9 to 12 on their well-being, parent relations, home life and self perceptions (Erhart et al, 2009). Comments from parents from the Davis et al study focused on self-esteem issues. "He seems more happy and relaxed and his confidence in himself has improved. I think he feels just like anyone else on top of a horse. He is always frustrated with his sporting abilities, but this horse riding has made him feel really good about himself." Comments by parents included statements on physical improvements, "At the start of the horse riding lessons she could not correct her own body to balance on the horse - but by lesson 9 she had a sense of correction and attempted to correct herself if she was off balance."

A study by Blinde and McClung (1997) offered the ability to cross measure a variety of disabilities through an interview based format of adult riders who participated in a study dealing with perceptions of the "physical and social selves of 
individuals with physical disabilities". This study looked at adults between the ages of 19 through 54, and dealt with a number of different disabilities, including cerebral palsy, traumatic brain injury, paraplegia, quadriplegia, muscular dystrophy and spina bifida. Through a specific interview guide that consisted of open-end questions, the participants were asked to assess their physical levels before becoming involved in the study, and then were asked open-ended questions upon competing recreational programs, including horse riding, from five to 24 weeks long.

Physical disabilities have the obvious advantage of being able to measure improvements with a wide variety of assessment scales. Early studies, such as the one often cited by researchers, Bertoti (1988), concentrated their efforts on cerebral palsy, which is a disability that has been consistently served well by therapeutic riding centers. The Horses and Humans Foundation (2009), which funds research projects that support the "claimed, yet unsubstantiated benefits of equine assisted activities and therapies" funded a major study on cerebral palsy in the year 2007. This study concluded that horseback riding improved motor control of the head and trunk, and that the effects and benefits of the therapy continued two months after the riding ceased (Shurtleff, Standeven \& Engsberg, 2009).

There are few recent studies focusing on the cognitive improvements from therapeutic riding (Bass et al, 2009). Cognitive disabilities are much more difficult to assess because of the variety and levels of the various disabilities that have a component of cognitive problems as part of a disability. Many physical disabilities 
have corresponding cognitive disabilities as well, but researchers often do not focus on the cognitive issues.

However, with autism now affecting 1 out 91 children (Kogan et al, 2009), the push has been made to study the effects of therapeutic riding and/or hippotherapy on children with autism. The Horses and Humans Foundation funded the Bass et al 2009 study that used two questionnaire based measurement tools, the Social Responsiveness Scale (SRS) and the Sensory Profile, to measure social functioning improvement and the severity of autism spectrum symptoms. Participants in the study improved in social motivation, sensory sensitivity, directed attention and sensory integration. The researchers concluded that therapeutic riding is a successful treatment strategy.

A 2006 study by Kaiser, Smith, Heleski, and Spence looked at the psychosocial measurements involved with therapeutic riding. Fourteen special education children and 17 at-risk children ages 10 through 18 were assessed on attitudes, including anger, behavior and cheerfulness before and after 8 weeks of therapeutic riding. Measurements for the at-risk children included the psychological evaluations of anger, anxiety and self-competence. Special education children had anger, cheerfulness and behavior measured. Psychological measurements did not significantly change for the at-risk children, but significant changes occurred in 3 of the 16 motor coordination measures. Anger scores decreased significantly for the special education children, and the mothers of the boys involved in the study perceived an improvement in their behavior. 
Research in the relatively new but growing specialties of Equine Facilitated Psychotherapy and Equine Learning (EFMHA, 2009) in equine assisted activities and therapies is very limited. A review of 12 research studies on equine facilitated psychotherapy by Lentini and Knox (2008) found positive outcomes, including "decrease in anger, depression, dissociation and aggression and increases in selfesteem, self-confidence, attention span, and social interaction." All studies involved used qualitative tools of measurement, from self-reporting to questionnaires. Through the examination of the studies available, the studies that focused on cognitive and emotional disabilities used qualitative assessment methods, and studies measuring improvements in physical disabilities used quantitative methods. This mirrors the problems that therapeutic riding instructors and centers face in producing viable assessments of their own, and how they can reliably measure outcomes and show progress on such different aspects of disabilities.

\section{Importance of Measuring Outcomes}

There are several important reasons for the measurement of outcomes for therapeutic riding students. The majority of NARHA centers are 501(c)(3) nonprofits and are funded through grants, private donations and fundraisers. Particularly in the case of funding from grants and foundations, centers need to justify their needs for money based on some type of concrete data to show that what they do has real effects on the participating riders. Personnel involved with NARHA centers would also have a clearer understanding of the benefits of their profession on their riders. Parents or caretakers of riders involved in programs should be 
involved in the measurement process, and, therefore, take pride in the "ownership" of providing meaningful data to the center's administrators.

Unfortunately, in spite of the obvious need for outcome measurement, the field of equine assisted activities and therapies is not the only professional field that has limits to its ability to research and measure outcomes. Based on a survey of members of the American Physical Therapy Association, physical therapists have difficulty in routinely using outcome measures in their practices (Jette et al, 2009). The main reason cited in the survey for not maintaining good measurement outcomes data was merely a lack of time. Other complaints by therapists included the inability to apply measurements to patients in their practice and/or they could not interpret scores. Mental health specialists also feel that performing assessments are "cumbersome and intrusive" according to a study by Garland, Kruse, and Aarons (2003). This creates a problem with the effectiveness of their practices, as quality of care may be based on theory instead of empirical evidence. The profession of speech-language pathology lacks effective instruments that accurately measure communication (Eadie et al, 2006).

Many professionals involved in therapeutic riding lament the lack of research and express interest in seeing research results (Splinter-Watkins, 2009) but the fact remains that the wide variety of disabilities served by centers has been a stumbling block to having an easy way to establish measurement methods. A study by Pauw (2000) reviewed measurement problems experienced by researchers involved in therapeutic riding studies. Pauw examined the results of studies where statistical tests were used and the results of studies involving case studies and descriptive 
statistics. The majority of studies using statistical analysis showed little or no significant change in participants, but the qualitative results based on parent, participant or instructor comments were always positive. Pauw suggests that "the positive clinical effects are not always reflected in the results of the statistical tests" and that small sample size used in most therapeutic riding research may decrease the ability of the statistical test to show significance.

\section{Current NARHA Standards on Record Keeping}

NARHA centers range from the very small, with one or two horses, one instructor and a handful of riders, to the very large, with over million dollar budgets and 30 or more full-time paid personnel. Regardless of size, NARHA training emphasizes the importance of lesson plans and progress reports. NARHA maintains a list of standards for center members to follow (NARHA, 2009). These standards are important in the implementation of best practices for both instructors and centers. The core standards fall into three clearly defined areas: administrative, program and facility. There are nine standards that are considered mandatory, and they are considered "significant in the assurance of safety precautions, certifications, and liability" (Table 1.). In addition to the nine mandatory standards for all NARHA centers, there are mandatory standards for any center offering a programming specialty, including driving, interactive vaulting, hippotherapy and equine facilitated psychotherapy.

All NARHA centers must comply with the standards regardless of accreditation status. There are two standards that apply to the process of assessing riders and measuring their outcomes. They are as follows: 
P (Program standard) 22:

Is there a procedure in practice which requires an initial written evaluation of each new participant which is readily available on-site?

Interpretation: Each new participant should be evaluated to establish an initial profile of abilities upon which the goals and objectives for each participant will be based.

P (Program standard) 25:

Is there a procedure in practice that requires written records of participant's progress and other activities readily available on-site?

Interpretation: Progress notes enable the instructor to document the participant's achievements and problem areas. It provides a method to re-evaluate and build upon previous goals and objectives. It is recommended that written update of progress be maintained on a regular basis.

The key word in program standard 25 is "required". Centers are required to keep progress reports, and file an annual compliance form with NARHA that the center is maintaining good practices and adhering to the standards. Premier Accredited NARHA Centers go through an on-site visit from members of NARHA accreditation specialists, and are required to demonstrate to the specialists that the center has an adequate method of record keeping to comply with Program

Standards 22 and 25.

\section{What Works, What Doesn't, What Can Be Done?}

Using instruments of measurement or assessment that require special circumstances or unease of participants is not useful for an ongoing program trying 
to maintain a constant stream of outcome measures. NARHA programs that have steadily developed and maintained a process of measurement that works well for them have readily shared their format with other NARHA center administrators through the convenience of Internet and the availability of a listserv (NARHA, 2010). This listserv is maintained solely for the purpose of exchanging ideas and information about NARHA center management and has been an excellent way of exchanging measurement formats and ideas for assessing riders that have unique challenges.

A well-traveled road for many children with disabilities involved with therapeutic riding programs is their dual involvement with the special education system in public school. As dictated by the Individuals with Disabilities Education Act (IDEA) legislation (U.S. Department of Education, 2010), children in special education are required to have Individualized Education Plans in place for them, which in effect, have specific goals and measurement outcomes in place (Tarver-Lee, 2006). Currently, some school systems utilize computer software to maintain these measurements. A suggestion here is to produce software that could be easily downloaded or purchased by NARHA centers. This could easily make what previously was a pen and pencil project into a simple point and click process, which may make it much easier to translate data collected on a weekly basis into a usable format for interpretation of data.

By encouraging participation in developing standardized formats for therapeutic riding programs, eventually it will become clear what format matched with groups of similar disabilities will work well enough to produce some 
measurable outcomes that can be touted as tangible proof that therapeutic riding works. This will solidify the justification for therapeutic riding from the viewpoint of donors to programs, as well as laying the groundwork for the understanding of the impact of therapeutic riding for other professions, including the medical establishment and those that provide services to those with disabilities.

\section{Training for Therapeutic Riding Instructors}

Therapeutic riding instructors are expected to have a solid background in horse care and handling, teaching skills for horseback riding, knowledge of disabilities, and knowledge of lesson plan writing and understanding rider progress. NARHA has developed a system of workshops that precede actual instructor evaluation certification exams, and these workshops cover the basics of lesson writing, with emphasis on writing goals and objectives (NARHA, 2009). The assumption exists that in writing goals and objectives that the instructor has the means to follow up with rider progress, whether in pen and pencil or on some type of computer notes as to whether the riding student met those goals and objectives. This is all part of the goals of maintaining good records so that progress of the riders can be maintained on a daily basis. The difficulty lies in the reality of the day-to-day operation of a typical therapeutic riding center. The instructors normally have back to back lessons, have the added responsibility of overseeing as many as three volunteers per horse, and depending on the center's lesson formats, may have up to five riders per lesson. Depending on the instructor's workload this translates into an extensive amount of record keeping on a daily basis. Part of the training of registered instructors must involve the use and proficiency of using types of 
standardized measurements to keep data on all riders/participants in their programs. These data can be put into a format for analysis on yearly basis for not only the center itself, but on a national and international level for NARHA, so it can begin to have a track record of the benefits of its programs. Computer based record keeping would give the greatest amount of versatility for compiling data for tallying results on the basis of instructor input.

Lesson planning with goals and objectives provides the tools to develop measurements, from identifying what the instructors see and hear from the participant, to what can be assessed from the parent's or caregiver's perspective. Questions about what abilities or skill improvements the parents and/or caregivers are seeing at home are important as well.

It is important to note that all riders are not children, as many adults with disabilities are regular participants in NARHA programs. NARHA estimates $22 \%$ of participants are over the age of 19. These adults often can assess their own progress and satisfaction of participation in the NARHA program they are involved with, but most research studies have focused on children.

\section{Therapeutic Riding and Education}

Another development over the last few years has been the partnership of therapeutic riding centers and public schools. The therapeutic riding service is written into the child's Individualized Education Plan, and the center services these students through group riding or stable management lessons. Following this structure makes it much easier to measure the outcomes of the students' learning, 
since the students have set criteria to follow, the centers can follow up what occurred during the session by recording what was accomplished and completed. Several NARHA centers have developed their own educationally based curriculum for riders involved in their programs. Fieldstone Farm in Cleveland, Ohio and Strides To Success, Inc. both NARHA equine-assisted activities and therapies center, have developed curricula that can be purchased and implemented in other NARHA programs. Fieldstone Farms' curriculum is based on the state of Ohio's educational standards in language arts, mathematics, science and social studies (Cruikshank et al, 2006). Strides to Success program is based on academic standards, but has much more emphasis on character building (Anderson \& Zimmerman, 2006). The program, named "Journey of the Spirit Horse" is targeted toward at-risk and disadvantaged children. Both the Fieldstone Farm and Strides to Success programs have distinct goals and objectives that can be translated into measurable outcomes.

Colleges and universities can positively affect the training of prospective therapeutic riding instructors by increasing their knowledge base and skill levels through the use of multidisciplinary curricula. A few colleges offer degrees in therapeutic horsemanship, and these graduates have the background and training to understand the importance and needs for measuring outcomes of riders. As NARHA develops its programming, training programs and certification methods for students enrolled in higher educational institutions, a component of the training should stress the importance of measuring outcomes, regardless of the level of NARHA instructor certification. 


\section{Survey Results}

A survey was sent by email in March of 2009 to NARHA Premier Accredited Centers regarding the use of assessments and/or measurement outcomes in their programs. A list of NARHA Premier Accredited Centers was obtained from the NARHA website. The NARHA Premier Accredited Center membership list included email addresses for contact. Five questions were sent to the 225 NARHA Premier Accredited Centers on the list, two of which related to measurement outcomes for the purposes of this article (Table 2.). The survey produced 27 viable responses (12\%) that represented a cross-section of size and location. Seventeen of the 27 respondents (7.5\%) included a copy of their measurement and/or assessment forms.

Center representatives and/or administrators answered two survey questions regarding their programs:

1. Could you briefly explain how your NARHA center measures the outcomes or progress of riders/participants in your therapeutic riding program? If you have a copy of any forms you use and would be interested in sharing with this project, it would be greatly appreciated.

2. If you do special assessments or measurements of outcomes or progress (other than what you provided above) with your participants with autism, could you share those as well?

As shown in Table 3, almost half of the centers (41\%) used written assessments, with no keeping any type of statistical data. The centers using a checklist (35\%) looked at a wide variety of skill ranges, from only assessing riding 
abilities to extremely detailed lists. Only $17 \%$ of the centers used scoring, or statistical means of assessing progress. One center did report they utilized all three methods within one form. The range in complexity of record keeping varied greatly. The simplest form was merely a listing of rider name, with progress notes written in beside the name. The most complex form was a very lengthy, detailed form that covered all aspects of skill progression and riders' disabilities. Several small centers used anecdotal notes, and did not formally keep records of any type.

The other aspect of the survey involved a separate format for those individuals with autism involved in therapeutic riding programs. Most centers reported that they utilized the same format for participants with autism as those of their other riders. Only one center reported using a separate form, which was an autism checklist developed by Dr. Bernard Rimland (Autism Research Institute, 2009).

An outstanding example of recording keeping, as well as demonstrating proof of improvement in rider progression, was shared by the Atlantic Riding Center for the Handicapped of Egg Harbor, New Jersey. Director Sue Adams sent a very detailed rider progress report that produced numerical values. These values were then translated into percentages that were individualized for each rider. This report is shared with parents and/or caregivers and produces a very clear and precise measurement of improvement. Ms. Adams produced her results using a spreadsheet, which could be produced through such software programs such as Microsoft Excel. 
Progress reports that had a checklist or numerical value as a component generally follow a format of distinguishing a list of riding skills from emotional, sensory integration, attention, behavior and speech/language improvements.

Some centers used forms that went into great detail on different aspects of the lesson itself. For example, one center form had standardized details on mounting and dismounting as part of their check-off list. The choices included what side of the horse the rider could mount from safely (near-side or off-side), and whether the rider needed assistance at three different levels (none, minimal or maximum). This same center broke down individual checklists for forms of communication (nonverbal, sign language, symbols, facial expressions, eye gazing, etc.), as well as details on sensory issues (tactile, auditory, vestibular, etc.).

Two centers responded that they used informal assessments based on parent/caregivers reports of how the riders translated their riding sessions into their everyday living, or functional outcomes. This is an important way to understand the total effects of therapeutic riding, because the goals of developing riding skills are also mingled with goals of making a positive impact on the rider's well being both physically and mentally. The transference effect of cognitive and physical skills gained from riding sessions to home and school use is just as important to measure as the on-site evaluation of the therapeutic riding instructor. Maintaining parent/caregiver observations may be an area that needs better followup by centers and instructors. Casual conversations can be carried out on a weekly basis by parents/caregivers or even the riders themselves that allow the riding 
instructors to understand how the therapeutic riding is helping other lifestyle aspects, but formal assessments, although subjective in nature, would be helpful.

A postural scoring scale that was developed as part of a master's thesis at the University of Florida is currently being utilized by several of the centers as part of their rider assessment. This scale, called the GREAT scale (Gainesville Riding through Equine Assisted Therapy), is a measurement instrument that allows a rater (or instructor) to judge the postural control of a rider with a disability (Frease, Walker \& Shectman, 2007). The GREAT scale used by the centers helps the instructor to visibly measure the progress of the rider's seat balance and ability to maintain posture in five different areas. These include head/cervical spine, shoulder/thoracic spine, pelvis/lumbar spine, hip angle, and knee flexion/heel orientation. Frease et al conducted a study of the interrator reliability of the GREAT scale, and concluded that the scale was a valid instrument of measurement. Suggestions for improvements on the GREAT scale included a training manual for those using the scale, and for better interrator reliability the riders should wear clothing that fits well.

Since therapeutic riding has the ultimate goal of the rider achieving independence, one respondent to the survey, Rebecca Cook, OT, HPCS, of the Right Step Therapy Services, developed a measurement form based on three areas of competency, which include balance, horse control and problem solving. Balance includes posture, range of motion and strength. Horse control is rated on ability to use the reins, which includes upper body control, and problem solving focuses on cognitive skills. This is an extremely easy but comprehensive measurement format 
that certainly covers all aspects of riding toward independence, and also includes horse care, equipment handling and knowledge and groundwork activities.

\section{Length and Type of Riding Sessions}

Most NARHA riding lessons are on average 30 minutes long. However, each center individually determines what constitutes a riding lesson length, as well as how many weeks in a riding session. Progress notes, evaluations and assessments can be done by lesson, by session, and by culmination of all sessions in a year's time. Lengths of sessions are determined by whether the center runs year-round, or weather dependent centers that either only have outdoor facility or are in cold climates. These sessions are often organized into spring, summer, fall or winter sessions of approximately six to twelve weeks.

Some NARHA centers also choose to incorporate ground activities, including managing horse equipment and tack, as well as grooming and brushing. These activities can push a riding lesson upwards to a full hour, yet gives the riding instructor opportunities to work on a larger variety of fulfilling activities with the rider, including the important bonding aspect of horse care. Several centers that provide these extra minutes of ground activities have rider progress and evaluations for these areas as well, including a checklist list of grooming, tacking and leading skills to listing specific knowledge areas, such as knowing the parts of the horse, the parts of the bridle and saddle, and advanced activities such as feeding, watering and bathing horses.

Another factor in how individual centers choose to chart rider progress and measure outcome is whether or not they offer group lessons. A NARHA instructor is 
trained to work with multiple riders. In order to pass at the basic level of registered therapeutic riding instructorship, a candidate must pass a teaching exam that involves two riders at one time. Larger centers tend to have more group lessons, whereas smaller centers often administer therapeutic riding lessons one-on-one. Group lessons, with sometimes up to five riders with similar disabilities, can be challenging for instructors to maintain detailed progress notes or evaluations on the riders. However, these large centers could produce the most data and proof of outcomes simply because of the sheer numbers of riders they serve. Once again, from an evaluation of the completed surveys, the larger centers tended to simplify their forms because of time constraints, and the smaller centers seemed to be able to take more time to individualize their assessments.

\section{Conclusion}

After analyzing the variety of ways different NARHA centers maintain their progress notes, assessments and outcome measures, it becomes apparent that perhaps one size will never fit all. Data collection through a scoring system appears to be the simplest method, however this type of assessment is limited by the subjectivity of the instructor. Group lessons of over two riders would be more difficult to assess, and it can be surmised that the larger NARHA centers are busier and have less time to keep good records. Although the future of these assessments will become more computer based, everyone involved in the work of the centers, including the participants, have a variety of ways of learning, thinking and understanding the different processes involved in therapeutic riding. Whether an instructor uses their own version of a rating scale, to the handwritten daily notes, 
not one method is wrong if in the end positive achievement and progress can be documented.

The problem that needs solved, however, is still the need to document what therapeutic riding centers do and why it works. The push is on to make the process electronically based, whether through software development on a computer or a hand-held device. Modern technology will go a great way to solve the record keeping aspects of the job of the therapeutic riding instructor, and obviously the young and newly minted instructors will have a much easier time of adapting to a format of electronic record-keeping. The argument will always be there for the more personal touch, such as the hand-written notes that can adequately explain what is being observed about an individual rider, but that, too, can be translated into a digital format.

The recommendations here, based on survey results, would be to maintain good daily written records of rider progress, but to perform assessments of riders on specific tasks on an eight to twelve week basis that can be measured numerically and, therefore, entered into an electronic database. Parent and/or caretaker assessments should be used as guides by therapeutic riding instructors for setting goals and objectives for individual participants. Choosing tasks to assess may depend on whether the program is therapeutic riding (riding skills) or hippotherapy (functional outcomes). It has been shown that cognitive skills level can be assigned numerical values, much like in the style that Sue Adams has developed for her program at the Atlantic Riding Center for the Handicapped, and physical improvement of balance and posture can also be assessed by the numerical values 
such as those used by the GREAT postural scale. The missing link here is the emotional variable, and that can addressed through parent or caretaker interviews at the beginning and end of the block of riding lessons (every eight to twelve weeks) and even yearly.

The field of therapeutic riding, and equine assisted activities in general, will have to adapt and find a middle ground of assessing rider progress and measuring outcomes. The middle ground may never become quite clear, as many therapeutic riding instructors come from a variety of backgrounds, some with occupational or physical therapy backgrounds, and others with strong equine based skills.

Therapeutic riding instructors may differ on what skills they believe are important to assess, and certain disabilities present much bigger challenges for assessment (such as autism), and will not easily translate into numbers in a database. Identifying what variables, such as riding skills, verbal abilities, etc., that would be the most important on which to keep assessments would be key to developing a standard assessment form.

A form designed by the author to meet the needs for therapeutic riding instructors' assessments or measurement outcomes can be found in Appendix C. The form is broken down into types of activities, including riding skills at the walk and trot (canter skills can be added as needed). Horse care, such as grooming, leading and tacking horses is included. A separate form for skill components (skills necessary to possess in order to perform the riding skills) include balance, posture and cognition. Each skill is rated on a scale of 1 to 5 , based on the percentage of attempts made to perform the skill, and therefore easily scored and totaled. If the 
form is used at the beginning of a session and at the conclusion (six to twelve weeks span of time), a progression in skills should easily be demonstrated statistically.

The advent of the new programming from NARHA and the promotion of the higher education membership/partnership with NARHA centers to colleges and universities will change the field in the future. Therapeutic riding instructors who are academically trained may have a better understanding of the need for record keeping and assessments. Instructors coming from college-based certification programs may help promote the need for keeping accurate assessments based on their training and knowledge acquired from a diverse curriculum.

Independent research is important and a valuable part of understanding the effects and value of therapeutic riding. However, the impact of data acquired over a long period of time from NARHA centers could make an enormous difference on the perception of the value of therapeutic riding. Developing measurable outcomes that can be used on a daily basis by NARHA centers could be resolved by some additional research that may survey a larger population of NARHA centers. Variables may include size of NARHA centers, time spent by instructors on manual record keeping, and format of lessons. Therapeutic riding instructors see the amazing miracles that happen on the back of a horse on a daily basis at NARHA centers worldwide. It is imperative that all of the good work that is accomplished at these centers with people with disabilities is verified by a consistent method of measuring participant outcomes. 
Mandatory standards are deemed to be significant in the assurance of safety precautions, certifications, and liability.

\section{Administrative Standards}

*A11 Does the center require a signed, dated, written waiver or release of liability available on-site from all participants, volunteers or from a participant's parent/legal guardian?

*A14 Does the center require for all participants, volunteers and personnel signed consent to seek emergency medical treatment, or a signed non-consent for medical treatment form to be available at each activity site?

\section{Program Standards}

*P12 Are participants, volunteers and personnel required to wear, and in fact do wear, protective headgear that is American Society for Testing and Materials - Safety Equipment Institute (ASTM-SEI) approved for equestrian use while mounted or driving? Helmets that are not ASTM-SEI approved for equestrian use must meet the NARHA Guidelines for Alternative Helmet Use. (See Guidelines)

*P13 Is there a written policy and procedure in practice regarding the use of stirrups with safety features $\mathbf{O R}$ is there a written policy in practice that participants wear riding boots or hard-soled shoes with heels?

*P14 Is there a procedure in practice to ensure that tack and equipment is safe, and in good repair?

*P20 Is there written evidence that all instructors directly supervising each equine assisted activity hold a NARHA recognized certification in the specific equine activity being held?

*P28 Is there written evidence that the direct service health professional conducting a therapy session at a center is licensed/credentialed to practice a particular nationally recognized health profession?

*P29 Is the health professional providing direct service either a NARHA Certified Instructor or assisted by a NARHA Certified Instructor during all equine related treatment sessions?

\section{Facilities Standards}

*F6 Does the center have:

1. An available working telephone or similar communication device in a designated location?

2. Emergency information posted adjacent to the telephone or similar communication device? 
Table 2. Premier Accredited NARHA Center survey

1. Could you briefly explain how your NARHA center measures the outcomes or progress of riders/participants in your therapeutic riding program? If you have a copy of any forms you use and would be interested in sharing with this project, it would be greatly appreciated.

2. If you do special assessments or measurements of outcomes or progress (other than what you provided above) with your participants with autism, could you share those as well? 
Table 3.

Measurement of Outcomes and/or Rider Progress for NARHA Centers

\begin{tabular}{|c|c|c|c|}
\hline NARHA Center & Format & Variables on Forms & $\begin{array}{l}\text { Comments and/or } \\
\text { self-evaluation of } \\
\text { center administrator }\end{array}$ \\
\hline Buffalo Therapeutic & Checklist & Riding skills & $\mathrm{N} / \mathrm{A}$ \\
\hline $\begin{array}{l}\text { Riding Center } \\
\text { People/Pet } \\
\text { Partnership }\end{array}$ & Checklist & $\begin{array}{l}\text { Communication } \\
\text { Muscle strength } \\
\text { Attitude, Coordination } \\
\text { Confidence, Balance, } \\
\text { Problem solving } \\
\text { Horsemanship }\end{array}$ & $\mathrm{N} / \mathrm{A}$ \\
\hline $\begin{array}{l}\text { Pikes Peak } \\
\text { Therapeutic Riding }\end{array}$ & Checklist & $\begin{array}{l}\text { Riding skills } \\
\text { Emotional levels } \\
\text { (confidence, attitude) } \\
\text { Weaknesses, strengths }\end{array}$ & $\mathrm{N} / \mathrm{A}$ \\
\hline Ride-Like-A-Knight & Checklist & $\mathrm{N} / \mathrm{A}$ & $\mathrm{N} / \mathrm{A}$ \\
\hline $\begin{array}{l}\text { Tarleton Equine } \\
\text { Assisted Therapy }\end{array}$ & Checklist & $\begin{array}{l}\text { Behavior, following } \\
\text { directions, balance, } \\
\text { posture, riding skills }\end{array}$ & $\begin{array}{l}\text { "Reports are brief } \\
\text { because college } \\
\text { students are making } \\
\text { the observations" }\end{array}$ \\
\hline Thorncroft & Checklist & Riding skills & $\begin{array}{l}\text { "We tweak NARHA } \\
\text { sample form for our } \\
\text { own use" }\end{array}$ \\
\hline $\begin{array}{l}\text { Atlantic Riding for } \\
\text { The Handicapped }\end{array}$ & Scoring & $\begin{array}{l}\text { Posture/balance } \\
\text { Attention/concentration } \\
\text { Vision, hearing, } \\
\text { awareness, organization }\end{array}$ & $\begin{array}{l}\text { "Point system } \\
\text { a must for } \\
\text { data collection" }\end{array}$ \\
\hline $\begin{array}{l}\text { The Right Step } \\
\text { Therapy Services }\end{array}$ & Scoring & $\begin{array}{l}\text { Riding skills, } \\
\text { balance, strength, } \\
\text { endurance, range of motion, } \\
\text { extremity control, strength } \\
\text { vision/hearing, awareness }\end{array}$ & N/A \\
\hline
\end{tabular}




\begin{tabular}{|c|c|c|c|}
\hline We Can Ride & Scoring & $\begin{array}{l}\text { Psychological/social, } \\
\text { neuromuscular, gross } \\
\text { motor control, dexterity, } \\
\text { cognition }\end{array}$ & $\begin{array}{l}\text { "Assessment } \\
\text { for the end of } \\
\text { session" }\end{array}$ \\
\hline Centenary College & Written & $\begin{array}{l}\text { Rider skills position, } \\
\text { use of aids, riding abilities, } \\
\text { unmounted skills }\end{array}$ & $\begin{array}{l}\text { Progress reports } \\
\text { done as a group } \\
\text { for different points } \\
\text { of view (goals, } \\
\text { objectives) }\end{array}$ \\
\hline $\begin{array}{l}\text { Charleston Area } \\
\text { Therapeutic Riding }\end{array}$ & Written & $\begin{array}{l}\text { Motor skills, speech } \\
\text { language, cognitive, } \\
\text { behavior, position }\end{array}$ & $\begin{array}{l}\text { Evaluations consist } \\
\text { of assessments, } \\
\text { recommendations, } \\
\text { goals }\end{array}$ \\
\hline Equibloom & Written & $\begin{array}{l}\text { Rider goals/ } \\
\text { Objectives/progress } \\
\text { notes }\end{array}$ & $\begin{array}{l}\text { Re-evaluated } \\
\text { quarterly }\end{array}$ \\
\hline $\begin{array}{l}\text { Horses and the } \\
\text { Handicapped }\end{array}$ & Written & Speech/language & $\mathrm{N} / \mathrm{A}$ \\
\hline $\begin{array}{l}\text { Kent Association } \\
\text { Of Riding Therapy }\end{array}$ & Written & $\mathrm{N} / \mathrm{A}$ & $\begin{array}{l}\text { Ancedotal, } \\
\text { re-evaluated } \\
\text { quarterly }\end{array}$ \\
\hline High Hopes & Written & Goals/Objectives & $\begin{array}{l}\text { Documentation at } \\
\text { each lesson }\end{array}$ \\
\hline $\begin{array}{l}\text { Riverwood } \\
\text { Therapeutic Riding } \\
\text { Center }\end{array}$ & Written & $\begin{array}{l}\text { Long term/ } \\
\text { Short term goals }\end{array}$ & $\begin{array}{l}\text { Forms are simply } \\
\text { updated as goals } \\
\text { change }\end{array}$ \\
\hline Windrush & $\begin{array}{l}\text { Checklist, } \\
\text { Scoring, } \\
\text { Written }\end{array}$ & G.R.E.A.T Postural Scale & $\mathrm{N} / \mathrm{A}$ \\
\hline
\end{tabular}




\section{References}

All, A. C., \& Loving, G. L. (1999). Animals, horseback riding, and implications for rehabilitation therapy. Journal of Rehabilitation, 65(3), 49-57.

Anderson, D. \& Zimmerman, L. (2006). Cowboy Poetry. (Available from Strides to Success, 3747 South County Road 1050 East, Indianapolis, IN 46231)

American Hippotherapy Association (2009). Retrieved August 23, 2009, from http://www. americanhippotherapyassociation.org/

Autism Research Institute (2009). Diagnostic checklist form e-2 and research questionnaire form e-3. Retrieved March 14, 2009, from http://www.autism.com/autism/first/e23.htm

Bass, M. M., Duchowny, C. A., \& Liabre, M. M. (2009). The effect of therapeutic horseback riding on social functioning in children with autism. Journal of Autism Developmental Disorders, 39(9), 1261-1267.

Bertoti, D (1988). Effect of therapeutic horseback riding on posture in children with cerebral palsy. Physical Therapy, 68(10), 1505-1512.

Blinde, E. M., \& McClung, L. R. (1997). Enhancing the physical and social self through recreational activity: accounts of individuals with physical disabilities. Adapted Physical Activity Quarterly, 14(4), 327-344.

Cruikshank, N., Harris, S., Sibley, S., Simak, L., Silliman, M. L., Kasunick, L. et al. (2006). Academic Enrichment Curriculum for Fieldstone Farm (Available from Fieldstone Farm, 16497 Snyder Road, Chagrin Falls, OH 44023) 
Davis , E., Davies, B., Wolfe, R., Raadsveld, R., Heine, B., Thomason, P., et al. (2008). A randomized controlled trial of the impact of therapeutic horse riding on the quality of life, health, and function of children with cerebral palsy. Developmental Medicine \& Child Neurology, 51(2), 111-119.

Debuse, D., Chandler, C., \& Gibb, C. (2005). An exploration of German and British physiotherapists' views on the effects of hippotherapy and their measurement. Physiotherapy Theory and Practice, 21(4), 219-242.

EFMHA (2009). What is EFMHA? Retrieved September 12, 2009 from http://www.narha.org/SecEFMHA/WhatIsEFMHA.asp

Eadie, T. L., Yorkston, K. M., Klasner, E. R., Dudgeon, B. J., Dietz, J. C., Baylor, C. R., et al. (2006). Measuring communicative participation: a review of self-report instruments in speech-language pathology. American Journal of SpeechLanguage Pathology, 15(4), 307-320.

Erhart, M., Ravens-sierberer, U., Dickinson, H. O., \& Colver, A. (2009). Rasch measurement properties of the KIDSCREEN quality of life instrument in children with cerebral palsy and differential item functioning between children with and without cerebral palsy. Value in Health, 12(5), 782-792.

Frease, L. A., Walker, K., \& Shechtman, O. (2007). Interrator reliability of the GREAT postural rating scale for therapeutic riding. In B. Engel \& J. MacKinnon (Eds.), Enhancing Human Occupation Through Hippotherapy (1st ed., pp. 76-88). Bethesda: The American Occupational Therapy Association, Inc. 
Garland, A. F., Kruse, M., \& Aarons, G. A. (2003). Clinicians and outcome measurement: what's the use? Journal of Behavioral Health Services \& Research, 30(4), 393-405.

Horses And Humans Research Foundation (2009). Awarded Projects. Retrieved September 12, 2009, from http://www.horsesandhumans.org/Research_AwardedProjects.html

Jette, D. U., Halbert, J., Iverson, C., Miceli, E., \& Shah, P. (2009). Use of Standardized Outcome Measures in Physical Therapist Practice: Perceptions and Applications. Physical Therapy, 89, 125-135.

Kaiser, L., Smith, K. A., Heleski, C. R., \& Spence, L. J. (2006). Effects of a therapeutic riding program on at-risk and special education children. Journal of American Veterinary Medical Association, 228, 46-52.

Kogan, M. D., Blumberg, S. J., Schieve, L. A., Boyle, C. A., Perrin, J. M., Ghandour, R. M., et al. (in press). Prevalence of parent-reported diagnosis of autism spectrum disorder among children in the US, 2007. Pediatrics, 124(5), 1395-1403.

Lentini, J. A., \& Knox, M. S. (2008). A Qualitative and Quantitative Review of Equine Facilitated Psychotherapy (EFP) With Children and Adolescents. The International Journal of Pyschosocial Rehabilitation, 13(1), 17-30.

Miller, J. H., \& Alston, A. J. (2004). Therapeutic riding: an educational tool for children with disabilities as viewed by parents. Journal of Southern Agricultural Research Education, 54(1), 113-123.

NARHA (2009). Who is NARHA? Retrieved September 22, 2009, from http://www.narha.org/WhoIsNARHA/About.asp 
NARHA (2009). Carriage Driving $Q \& A$. Retrieved October 24, 2009, from http://www.narha.org/Driving/Driving_QandA.asp

NARHA (2009). NARHA 2009 Fact Sheet. Retrieved August 10, 2009, from http://www.narha.org/PDFfiles/2009NARHAFactSheet.pdf

Pauw, J. (2000). Therapeutic horseback riding studies:problems experienced by researchers. Physiotherapy, 86(10), 523-527.

Preston, D., \& Carter, M. (2009). A review of the efficacy of the picture exchange communication system intervention. Journal of Autism \& Developmental Disorders, 39(10), 1471-1486.

Shurtleff, T. L., Standeven, J. W., \& Engsberg, J. R. (2009). Changes in dynamic trunk/head stability and functional reach after hippotherapy. Physical Medicine and Rehabilitation, 90(7), 1185-1195.

Silkwood-Sherer, D., \& Warmbier, H. (2007). Effects of hippotherapy on postural stability in persons with multiple sclerosis: a pilot study. Journal of Neurologic Physical Therapy, 31(2), 77-84.

Splinter-Watkins, K. (2009). Research: past future. How far have we come? How far have we to go? Retrieved October 24, 2009, from http://www.narha.org/PDFfiles/research.pdf

Tarver-Lee, A. (2006). Are individualized education plans a good thing? A survey of teachers' perceptions of the utility of IEPs in regular education setting. Journal of Instructional Psychology, 33(4), 263-272. 
United States Department of Education, Office of Special Education (n.d.). Building the Legacy of IDEA 2004. Retrieved November 26, 2010, from http://idea.ed.gov/explore/home 
APPENDIX A: Measurement Outcome Form for Autism Disorder

\begin{tabular}{l|l|l} 
Participant: & Equipment: & $\begin{array}{l}\text { Beginning } \\
\text { of session }\end{array}$ \\
Date: & Volunteers: & \\
Instructor/Evaluator: & $\begin{array}{l}\text { End of } \\
\text { Session }\end{array}$ \\
\hline Speech/language/communication & $\begin{array}{l}\text { Scoring } \\
1-\text { Not true } \\
\text { 2-Somewhat true } \\
\text { 3-Very true }\end{array}$ & Score \\
\hline Can follow some commands & Comments & \\
\hline Can use appropriate gestures & & \\
\hline Can use one word at a time & & \\
\hline Can use two words at a time & & \\
\hline Knows 10 or more words & & \\
\hline Explains what he/she wants & & \\
\hline Asks meaningful questions & & \\
\hline $\begin{array}{l}\text { Has normal ability to communicate } \\
\text { for his/her age } \\
\text { Often uses several successive }\end{array}$ & & \\
\hline Appropropriate verbal restraint & & \\
\hline & & \\
\hline & & \\
\hline
\end{tabular}




\begin{tabular}{|c|c|c|}
\hline Sociability & $\begin{array}{l}\text { Scoring } \\
1 \text { - Very descriptive } \\
2 \text { - Somewhat descriptive } \\
3 \text { - Not descriptive } \\
\end{array}$ & Score \\
\hline & Comments & \\
\hline $\begin{array}{l}\text { Uncooperative/Resistant to } \\
\text { instruction }\end{array}$ & & \\
\hline Pays little attention when addressed & & \\
\hline No eye contact & & \\
\hline Shows no affection & & \\
\hline $\begin{array}{l}\text { Not able to imitate visual } \\
\text { demonstrations }\end{array}$ & & \\
\hline Disagreeable & & \\
\hline Rarely smiles & & \\
\hline Does not share or show & & \\
\hline Insensitive to humans and animals & & Total \\
\hline
\end{tabular}




\begin{tabular}{|c|c|c|}
\hline Sensory/Cognitive & $\begin{array}{l}\text { Scoring } \\
1 \text { - Not descriptive } \\
2 \text { - Somewhat descriptive } \\
3 \text { - Very descriptive }\end{array}$ & Score \\
\hline & Comments & \\
\hline \multicolumn{3}{|l|}{ Responds to name } \\
\hline \multicolumn{3}{|l|}{ Responds to praise } \\
\hline \multicolumn{3}{|c|}{ Appropriate facial expressions } \\
\hline \multicolumn{3}{|l|}{ Aware of environment } \\
\hline \multicolumn{3}{|l|}{ Touch sensitivity } \\
\hline \multicolumn{3}{|c|}{ Initiates and/or suggests activities } \\
\hline \multicolumn{3}{|l|}{ Curious/Shows interest } \\
\hline & & Total \\
\hline
\end{tabular}




\begin{tabular}{|c|c|c|}
\hline Physical Behavior & $\begin{array}{l}\text { Scoring } \\
1 \text { - Serious problem } \\
2 \text { - Minor/moderate problem } \\
3 \text { - Not a problem }\end{array}$ & Score \\
\hline & Comments & \\
\hline \multicolumn{3}{|l|}{ Sound-sensitive } \\
\hline \multicolumn{3}{|l|}{ Anxious/fearful } \\
\hline \multicolumn{3}{|l|}{$\begin{array}{l}\text { Repetitive behaviors (rocking, self- } \\
\text { stimulation) }\end{array}$} \\
\hline \multicolumn{3}{|l|}{$\begin{array}{l}\text { Acts out toward team members or } \\
\text { horse }\end{array}$} \\
\hline \multirow[t]{2}{*}{$\begin{array}{l}\text { Adheres to rigid routines } \\
\text { (i.e. upset with change of horse, } \\
\text { volunteers, etc.) }\end{array}$} & & \\
\hline & & Total \\
\hline
\end{tabular}


APPENDIX B: College or University Department and Course Suggestions for EAAT

Possible college departments with courses or minors (for a multidisciplinary approach) that could be utilized for EAAT curricula at the undergraduate level:

Equestrian studies, equine science, equine management

Business/Agribusiness

Special Education

Psychology

Rehabilitation Counseling

Disability Studies

Health Sciences (anatomy, occupational therapy, physical therapy)

Speech Language Pathology

Recreation Therapy

Exercise Physiology

Types of courses or suggestions for courses that meet EAAT/NARHA certification needs:

\section{Equine Courses}

Safety and Handling/Understanding Horse Behavior

Training/Natural Horsemanship/Theories of Training

Training the Therapy Horse

Equine Anatomy/Physiology

Equine \& Stable Management (history, breeds, care, diseases, tack, etc.)

Facility Design and Development

Equitation (several skill levels)

Historical Perspectives of the Horse-Human Relationship

Psychology Courses

Counseling Skills

Introduction to Psychology

Child \& Adolescent Psychology

Crisis Intervention/Management

\section{Teaching Courses}

Teaching Methods for Riding

Teaching Methods for Therapeutic Riding

Educational Psychology

Learning \& Cognition

Small Group Communication 


\section{Business}

Enterprise Operation and Law

Entrepreneurship (writing a business plan, marketing, etc.)

Non-profit management

Accounting

Leadership

\section{Disabilities}

Developmental Disabilities

Disability and Society (history, laws)

Disability and the Community

Psychosocial Aspects of Disabilities

Medical Aspects of Disabilities

Adaptive Physical Education

\section{Health Sciences}

Anatomy

Kinesiology

Human Physiology

\section{Specific TR Course suggestions:}

Foundations of Equine Assisted Activities and Therapies

Therapeutic Riding Track

Mental Health Track (Equine Facilitated Psychotherapy/Equine Facilitated

Learning)

Therapeutic Riding Business Administration

Medical and/or Psychosocial Aspects of Disabilities in Equine Assisted Activities and Therapies

NARHA Certification I \& II 
APPENDIX C: Measurement Outcome Form for Therapeutic Riding Participants

\begin{tabular}{|c|c|c|}
\hline $\begin{array}{l}\text { Participant Name: } \\
\text { Date: }\end{array}$ & $\begin{array}{l}\text { Scoring Scale: } \\
1 \text { - No attempt/Unable } \\
2 \text { - Attempts rarely with assistance ( } 25 \% \text { of the time or less) } \\
3 \text { - Attempts occasionally with assistance (50\% of the time) } \\
4 \text { - Independent with some assistance ( } 75 \% \text { of the time) } \\
5 \text { - Independent }\end{array}$ & $\begin{array}{l}\text { Beginning } \\
\text { of session }\end{array}$ \\
\hline Instructor: & Volunteer needs: & \\
\hline Horse: & Equipment needs: & $\begin{array}{l}\text { End of } \\
\text { session }\end{array}$ \\
\hline Type of Activity & Comments (Including limiting factors) & Score \\
\hline $\begin{array}{l}\text { Mounting } \\
\text { Type: }\end{array}$ & & \\
\hline $\begin{array}{l}\text { Dismounting } \\
\text { Type: }\end{array}$ & & \\
\hline Riding Skills/Walk & & \\
\hline Rein control & & \\
\hline $\begin{array}{l}\text { Maintains correct } \\
\text { balance/posture }\end{array}$ & & \\
\hline Halt & & \\
\hline Transitions & & \\
\hline Two-point & & \\
\hline
\end{tabular}




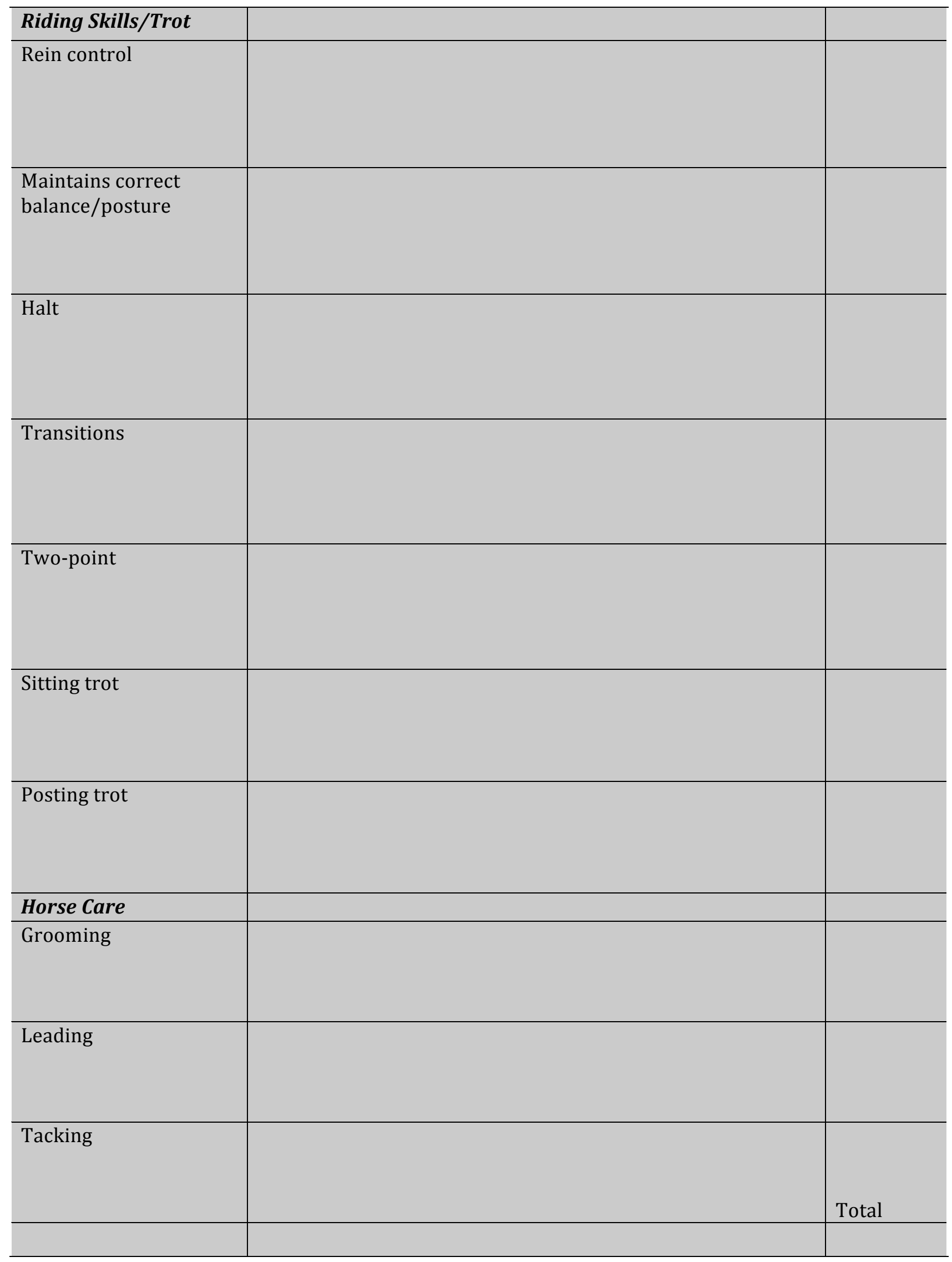




\begin{tabular}{l|l|l}
\hline Skill Components & & \\
\hline Balance/Posture & Comments (Including limiting factors) & Score \\
\hline Head Control & & \\
\hline $\begin{array}{l}\text { Upper extremity } \\
\text { control }\end{array}$ & & \\
\hline $\begin{array}{l}\text { Seat balance - } \\
\text { Nentered }\end{array}$ & & \\
\hline Leg/heel position & & \\
\hline Reaching & & \\
\hline Crossing midline & & \\
& & \\
\hline Cognition & & \\
\hline Memory & & \\
\hline Receptive language & & \\
\hline Attention/Focus & & \\
& & \\
\hline Expressive language & & \\
\hline & & \\
\hline & & \\
\hline
\end{tabular}

